\title{
Enhanced Adult Neurogenesis and Angiogenesis and Altered Affective Behaviors in Mice Overexpressing Vascular Endothelial Growth Factor 120
}

\author{
Hiroshi Udo, ${ }^{1}$ Yuka Yoshida, ${ }^{1}$ Takako Kino, ${ }^{2}$ Koichiro Ohnuki, ${ }^{2}$ Wataru Mizunoya, ${ }^{3}$ Takao Mukuda, ${ }^{4}$ and \\ Hiroyuki Sugiyama ${ }^{1}$ \\ ${ }^{1}$ Department of Biology, Faculty of Science, and ${ }^{3}$ Department of Bioscience and Biotechnology, Faculty of Agriculture, Kyushu University, Fukuoka 812- \\ 8581, Japan, ${ }^{2}$ Evaluation and Management Department, User Science Institute, Kyushu University, Fukuoka 815-8540, Japan, and ${ }^{4}$ Department of Human \\ Science, Faculty of Integrated Arts and Sciences, Hiroshima University, Hiroshima 739-8521, Japan
}

\begin{abstract}
Vascular endothelial growth factor (VEGF) is implicated as a molecular mediator for adult neurogenesis and behavioral effects of antidepressant drugs. However, these potential roles of VEGF in the CNS have not been clarified in model animals. Here we have created transgenic mice overexpressing a short active variant of VEGF-A (VEGF120) in forebrain. Expression of VEGF120 significantly enhanced cell proliferation and angiogenesis, as exemplified by the formation of an enlarged reddish brain. Adult neurogenesis in hippocampus was markedly stimulated without affecting cell differentiation of neural progenitor cells. Hippocampal neurogenesis was particularly robust in young adult animals, but it declined with age and reduced to control levels by 20 weeks under continuous expression of VEGF120. Thus, VEGF alone is not sufficient to support the long-term enhancement of adult neurogenesis, and VEGF-induced vascularization per se does not necessarily predict increased neurogenesis. In transgenic mice, we observed significant changes in affective behaviors. VEGF was found to have not only antidepressant effects but also anxiolytic effects. In addition, we found that VEGF significantly reduced fear and aggression. In contrast, basal activities under natural conditions were not affected much. Unexpectedly, these characteristic behaviors were maintained in older transgenic mice undergoing a reduced level of cell proliferation in hippocampus, suggesting that there is potential dissociation between adult neurogenesis and mood regulation. Our data indicate that VEGF exerts strong neurogenic and angiogenic effects in postnatal brain and influences different forms of affective behaviors.
\end{abstract}

Key words: growth factor; neurogenesis; hippocampus; depression; anxiety; fear; aggression

\section{Introduction}

Vascular endothelial growth factor (VEGF) is known to be an essential angiogenic factor that stimulates proliferation of vascular endothelial cells (VECs) (Neufeld et al., 1999). In the CNS, VEGF and its receptors are widely expressed, not only in VECs but also in neurons, astrocytes, and neural progenitor cells (NPCs) (Stone et al., 1995; Maurer et al., 2003; Cao et al., 2004). Recent studies suggest that VEGF exerts pleiotropic effects on brain functions including enhancement of adult neurogenesis through direct activation of NPCs (Jin et al., 2002). VEGF is induced by various environmental factors such as voluntary exercise, enriched environment, learning tasks, and brain insults (Papavassiliou et al., 1997; Fabel et al., 2003; Cao et al., 2004). Interestingly, these stimuli are also known to significantly enhance hippocampal neurogenesis (Kempermann et al., 1997;

Received Aug. 4, 2008; revised Nov. 11, 2008; accepted Nov. 13, 2008.

This work was supported by the Japan Society for the Promotion of Science (Grant 18500297). We thank Dr. T. Ishihara for the critical review of this manuscript, Dr. T. Kitamura for helpful discussion, and Dr. Y. Toh for the use of the equipment.

Correspondence should be addressed to Dr. Hiroshi Udo, Department of Biology, Faculty of Science, Kyushu University, 6-10-1 Hakozaki, Higashi-ku, Fukuoka 812-8581, Japan. E-mail: hudouscb@mbox.nc.kyushu-u.ac.jp. D01:10.1523/JNEUROSCI.3673-08.2008

Copyright $\odot 2008$ Society for Neuroscience $\quad$ 0270-6474/08/2814522-15\$15.00/0
Gould et al., 1999; van Praag et al., 1999; Magavi et al., 2000; Gage, 2002), suggesting that VEGF may promote adult neurogenesis in response to external stimuli (Yasuhara et al., 2004; During and Cao, 2006).

Recently, antidepressant effects of VEGF have been suggested. A pharmacological approach by Warner-Schmidt and Duman (2007) has shown that administration of VEGF receptor antagonists diminishes both hippocampal neurogenesis and behavioral effects of antidepressant drugs. This is in good agreement with a previous report that hippocampal neurogenesis is required for the effects of antidepressant drugs (Santarelli et al., 2003). Thus, these observations raise the possibility that VEGF may exert antidepressant effects as a result of enhanced neurogenesis. However, the correlation between adult neurogenesis and clinical depression is still under debate (Lledo et al., 2006), and the real effects of VEGF on hippocampal neurogenesis and affective behaviors have not been demonstrated in model animals.

To dissect the mechanism, we have created mice overexpressing VEGF120 in forebrain. We have used this strategy because the general or brain-specific knock-out of VEGF-A is known to be lethal (Ferrara et al., 1996; Raab et al., 2004). Although transgenic (TG) mice overexpressing human VEGF165 in brain have been reported (Wang et al., 2005), the effects of VEGF on hippocampal 
neurogenesis and animal behaviors remain unknown. In this study, we used a short active variant of VEGF-A, VEGF120 (VEGF121 in humans), rather than VEGF164 (VEGF165 in humans) to specify the signaling pathway through VEGF receptors (Flt-1 and Flk-1) but not neuropilins involved in many biological functions such as axon guidance (Fujisawa, 2004; Moretti et al., 2006; Staton et al., 2007). In this manner, we can also minimize the potential side effects on brain development. VEGF120 TG mice exhibited a significant increase in hippocampal neurogenesis as well as angiogenesis in forebrain. The mice showed profound differences in several forms of affective behaviors. Our data demonstrated the multiple roles of VEGF in the CNS and provided novel evidence that VEGF plays important roles in mood regulation.

\section{Materials and Methods}

TG mice

A cDNA of mouse VEGF120 was cloned by reverse transcription-PCR with total brain RNAs (C57BL/6N) as templates. After confirmation of DNA sequences, VEGF120 cDNA was subcloned into an exon-intron cassette under control of a calcium/calmodulin-dependent protein kinase II (CaMKII $\alpha$ ) promoter (Mayford et al., 1995). The linearized DNA fragment was injected into oocytes from DBF1 mice (SLC), and four founders (F0) were obtained. Two of four lines transmitted the transgene to the F1 generation, and they were backcrossed to C57BL/6N wild-type (WT) mice at least five times. The TG mice were maintained as heterozygotes. The backcross to $\mathrm{C} 57 \mathrm{BL} / 6 \mathrm{~N}$ gave rise to nearly equal percentages of WT and TG progenies. WT littermates served as controls. Both male and female mice $(3,6,10,20$, and 50 weeks old) were used for experiments, except that only male mice (10, 15, and $30 \pm 2$ weeks old) were used for behavioral studies. Mice were housed at $23^{\circ} \mathrm{C}$ with $12 \mathrm{~h}$ light/ dark cycles (lights on 8:00 A.M. to 8:00 P.M.) and received food and water ad libitum. Animal experiments were conducted in accordance with the institutional guidelines at Kyushu University.

\section{Voluntary exercise}

Three-week-old male mice were randomly assigned into two groups of controls and runners. Runners were transferred to cages equipped with a running wheel (cage, $25 \mathrm{~cm}$ wide $\times 35 \mathrm{~cm}$ high $\times 40 \mathrm{~cm}$ deep; running wheel, $16 \mathrm{~cm}$ diameter $\times 8.5 \mathrm{~cm}$ deep). Control mice were housed in the cages without the wheel. Runners had free access to the running wheel for voluntary exercise. After 3 weeks, both controls and runners (6 weeks old) were killed for cytochemical analyses. The number of wheel rotations was automatically counted by an infrared sensor-based electronic preset counter (Keyence). The total running distances were calculated from the number of wheel rotations. There was no difference in the total running distances between genotypes.

\section{In situ hybridization}

In situ hybridization was performed as described previously (SchaerenWiemers and Gerfin-Moser, 1993). Briefly, brains were quickly isolated from 6-week-old mice and frozen in OCT compound (Tissue-Tek) at $-80^{\circ} \mathrm{C}$. The sagittal brain sections $(40 \mu \mathrm{m}$ thickness, $\sim 1 \mathrm{~mm}$ from the midline) were prepared with a cryostat (Leica) at $-20^{\circ} \mathrm{C}$ and mounted on glass slides. The digoxigenin (DIG)-labeled antisense and sense RNA probes corresponding to the entire mouse VEGF120 sequence $(\sim 0.5$ $\mathrm{kbp}$ ) were synthesized in vitro (Roche) and used at a concentration of 200 $\mathrm{ng} / \mathrm{ml}$ in hybridization solution. The antisense probe recognizes both the VEGF120 transgene and endogenous VEGF-A splice variants (including VEGF120, VEGF164, and VEGF188). The sense probe was used to evaluate the background signals. The mRNA signals were detected by the immuno-enzyme technique using alkaline phosphatases conjugated to anti-DIG antibodies. As a positive control, endogenous VEGF-A mRNAs were induced by hypoxia in WT mice, in which mice were placed in a nitrogen-filled chamber for $20 \mathrm{~s}$ for three times at $5 \mathrm{~min}$ intervals and then killed after $4 \mathrm{~h}$. For comparisons, brain sections from WT mice, hypoxic WT mice, and line 1 and 2 TG mice were mounted on the same glass slides to minimize possible staining variation. The images shown in Figure $1 A$ were obtained from samples on the same glass slide.

\section{5-Bromo-2'-deoxyuridine labeling}

To evaluate cell proliferation and differentiation, 5-bromo-2' deoxyuridine (BrdU; $100 \mathrm{mg} / \mathrm{kg}, 10 \mathrm{ml} / \mathrm{kg}$, i.p.) was administered to mice. For analysis of cell proliferation, mice at 3, 6, 10, 20, or 50 weeks of age were killed $2 \mathrm{~h}$ after a single injection of BrdU. For analysis of cell differentiation, 6-week-old mice were given four injections of BrdU (once daily, 4 consecutive days) and killed after 4 weeks (10 weeks old).

\section{Western blot analysis}

Whole brains or different brain regions (olfactory bulb, cerebral cortex, striatum, hippocampus, thalamus, cerebellum) were isolated from WT and TG mice at $6,10,30$, and 50 weeks of age. The brain tissues were weighed, sonicated in $10 \times$ volume of $1 \%$ SDS on ice, and frozen/stored at $-80^{\circ} \mathrm{C}$. The equal amounts of protein samples $(\sim 20 \mu \mathrm{g})$ in SDS sample buffer were subjected to SDS-PAGE [15\% gel for VEGF and brainderived neurotrophic factor (BDNF); $12 \%$ gel for Flk-1, Nestin, and $\beta$-tubulin] and blotted onto a polyvinylidene difluoride membrane (Bio$\mathrm{Rad})$. The membrane was pretreated with a blocking solution (5\% skim milk, $0.1 \%$ Tween 20 in PBS) overnight at $4^{\circ} \mathrm{C}$ and reacted with primary antibodies against VEGF (1:1000, rabbit polyclonal; Millipore Bioscience Research Reagents), BDNF (1:250, mouse monoclonal; Promega), Flk-1 (1:2000, mouse monoclonal; Santa Cruz Biotechnology), Nestin (1:250, mouse monoclonal; Millipore Bioscience Research Reagents), and $\beta$-tubulin (1:5000, mouse monoclonal; Sigma) in blocking solution for $2 \mathrm{~h}$. Membranes were washed with a washing solution $(0.1 \%$ Tween 20 in PBS) six times for 5 min each and reacted with horseradish peroxidaseconjugated secondary antibodies against mouse or rabbit IgGs (1:2000; NEB) in a blocking solution for $1 \mathrm{~h}$. The membrane was washed with a washing solution six times for $5 \mathrm{~min}$ each and rinsed with distilled water three times. The protein signals were detected by chemiluminescence [Lumi-Light Plus (Roche); exposed to x-ray film (RX-U; Fuji)].

\section{Immunocytochemistry}

Mice were fixed by intracardiac perfusion with $4 \%$ paraformaldehyde in PBS under anesthetization. Brains were removed, postfixed with $4 \%$ paraformaldehyde overnight at $4^{\circ} \mathrm{C}$, cryoprotected with $30 \%$ sucrose overnight at $4^{\circ} \mathrm{C}$, embedded in OCT compound (Tissue-Tek), and frozen/stored at $-80^{\circ} \mathrm{C}$. A series of $40 \mu \mathrm{m}$ coronal sections from different brain regions including cerebral cortex, striatum, hippocampus, and cerebellum were obtained with a cryostat (Leica). Brain sections were collected at $120 \mu \mathrm{m}$ intervals for cortex/striatum (corresponding region, $0.38-1.10 \mathrm{~mm}$ bregma; approximately six sections per pool, three pools), at $200 \mu \mathrm{m}$ intervals for hippocampus (corresponding region, -2.70 to $-1.46 \mathrm{~mm}$ bregma; approximately six sections per pool, five pools), and at $80 \mu \mathrm{m}$ intervals for cerebellum (corresponding region, -6.24 to -5.80 $\mathrm{mm}$ bregma; approximately six sections per pool, two pools) and transferred to multiwell plates containing PBS. For BrdU staining, sections were pretreated with $50 \%$ formamide $/ 2 \times$ SSC for $1 \mathrm{~h}$ at $65^{\circ} \mathrm{C}$, soaked in $2 \times$ SSC for $5 \mathrm{~min}$, denatured with $1 \mathrm{~N} \mathrm{HCl}$ for $30 \mathrm{~min}$ at $37^{\circ} \mathrm{C}$, neutralized with $0.1 \mathrm{~m}$ borate buffer, $\mathrm{pH} 8.2$, for $10 \mathrm{~min}$, and washed three times with PBS for 5 min each. For immunofluorescent staining, free-floating brain sections were first treated with blocking solution (3\% donkey serum, $0.1 \%$ Triton X-100, $0.05 \%$ Tween 20 in PBS) for $1 \mathrm{~h}$ and reacted with primary antibodies against $\mathrm{BrdU}$ ( $1: 400$, rat monoclonal; Abcam), VEGF (1:200, rabbit polyclonal; Millipore Bioscience Research Reagents), NeuN (1:400, mouse monoclonal; Millipore Bioscience Research Reagents), GFAP (1:400, rabbit polyclonal; Sigma), Nestin (1:400, mouse monoclonal; Millipore Bioscience Research Reagents), or Doublecortin (Dcx; 1:400, rabbit polyclonal; Abcam) in blocking solution for $2 \mathrm{~d}$ at $4^{\circ} \mathrm{C}$. Sections were washed six times with PBS for 5 min each, soaked in blocking solution for $10 \mathrm{~min}$, and reacted with donkey IgG secondary antibodies conjugated to FITC, Cy2, Cy3, or Cy5 against mouse, rat, or rabbit IgGs (1:200; minimal cross-species reactivity; Jackson ImmunoResearch) in blocking solution overnight at $4^{\circ} \mathrm{C}$. Sections were washed six times with PBS for 5 min each and mounted on slide glasses. Cell nuclei were stained with Syto13 green (1:2000; Invitrogen), which was included in a secondary antibody solution. Immunostaining with sec- 
ondary antibodies alone yielded no apparent nonspecific signals. For comparison of fluorescent intensities, brain sections from WT and TG mice were pretreated and stained together in the same wells, placed onto glass slides side by side, and imaged under the same microscope settings.

\section{Imaging and analysis}

Specimens were examined under a LSM510 laser-scanning confocal microscope (Zeiss) using argon and helium lasers at 488, 543, and $633 \mathrm{~nm}$. The laser intensity, scan speed, and gain were adjusted to avoid saturation and photobleaching. For each experiment, the same optimized conditions were applied to a series of samples. Original imaging data were acquired and viewed with the LSM Image Browser (Zeiss). For counting BrdU-positive cells, immunofluorescent images were taken with a $10 \times$ lens at $40 \mu \mathrm{m}$ optical thickness. For identification of cell types and capillaries, a series of $z$-sections at $1-4 \mu \mathrm{m}$ optical thickness were taken with a $20 \times$ [numerical aperture (N.A.) 0.7] or $40 \times$ (N.A. 1.3, oil) objective lens. To create composite images for the entire brain sections (as in Fig. $2 C$ ), multiple images obtained with a $5 \times$ objective lens were aligned by Adobe Photoshop (Adobe).

\section{Measurement of BrdU-positive cells in dentate gyrus}

A series of $40 \mu \mathrm{m}$ coronal sections were prepared from the hippocampal region (600-1800 $\mu \mathrm{m}$ region from the rostral end of hippocampus; corresponding region, -2.70 to $-1.46 \mathrm{~mm}$ bregma). Brain sections at 200 $\mu \mathrm{m}$ intervals were pooled in multiwell plates (approximately six sections per pool, five pools) and used for immunostaining. Immunofluorescent images were acquired from both left and right hippocampi for each section (total, $\sim 12$ images per mouse). We used a linear density of BrdUpositive cells [the number of cells per millimeter of subgranular zone (SGZ) ] as an indicator for cell genesis (Kitamura et al., 2003). The length of SGZs was measured by the LMS Image Browser (Zeiss) on images of Syto13 green nuclear staining. BrdU immunofluorescent images were converted into binary formats with a threshold at $50 \%$ of the maximal intensity by Image [National Institutes of Health (NIH), Bethesda, $\mathrm{MD}$ ]. The regions of interest [including SGZ and granule cell layer (GCL), but not hilus] were first outlined on images of nuclear staining and then superimposed on BrdU immunofluorescent images, and the number BrdU-positive cells within the region were automatically counted by ImageJ. The average linear densities of BrdU-positive cells along the SGZ were calculated for each mouse (based on $\sim 12$ images per mouse).

\section{Measurement of capillaries}

We used a lectin-based method to specifically label blood capillaries (Thurston et al., 1996). Briefly, brain sections containing cerebral cortex, hippocampus, or cerebellum were first stained with biotin-conjugated Lycopersicon esculentum (tomato) lectin ( $1 \mu \mathrm{g} / \mathrm{ml}$; Sigma) and then detected with avidin-Cy5 (1:200; Jackson Immunoresearch). For comparison of fluorescent intensities, sections from WT and TG mice were stained in the same wells, placed onto the same glass slides, and imaged under the same conditions. For the analysis of capillary diameters, lectinstained capillaries in polymorphic regions of dentate gyrus were randomly selected (total of 200 capillaries from three mice per genotype), and the minor axes of capillaries were measured by the LMS Image Browser (Zeiss). For the proliferating VECs, mice were labeled with BrdU for $2 \mathrm{~h}$ in vivo, and a series of brain slices ( $40 \mu \mathrm{m}$ thickness, four to six slices per mice, $200 \mu \mathrm{m}$ intervals in hippocampus) were triple stained with the lectin, anti-BrdU antibody, and Syto13 green. The $z$-series of fluorescent images were taken, and polymorphic regions of dentate gyrus were examined. BrdU/lectin-double positive cells with a smaller nucleus $(\sim 5 \mu \mathrm{m})$ on capillaries were identified as proliferating VECs. After counting the number of proliferating VECs, the cell densities (cells/ $\mathrm{mm}^{3}$ ) were then calculated.

\section{Behavioral analysis}

All behavioral studies were performed in adult male mice of indicated ages $(10,15$, or $30 \pm 2$ weeks old). WT and TG mice were housed together (total of four to six mice per cage, equal numbers of WT and TG mice in most cases). WT littermates were used as controls. The apparatus and data acquisition/analysis software for mood-related behaviors were de- signed and manufactured by O'Hara \& Company. The software used for the behavioral analysis (Image OF, Image EP, and Image FZ) was based on Image $(\mathrm{NIH})$.

Open-field test. Exploratory drive to a novel open field was measured with an open-field apparatus (white Plexiglas; $50 \mathrm{~cm}$ wide $\times 50 \mathrm{~cm}$ high $\times 30 \mathrm{~cm}$ deep) under bright ambient conditions (500 lux). Mice were placed in the defined corner of the apparatus, and the activities were recorded with a video camera for $10 \mathrm{~min}$. Total distance (centimeters) and time spent in the central part of the open field (seconds) were automatically analyzed using Image OF software.

Elevated plus maze. The platform of the elevated plus maze consisted of two closed arms (white Plexiglas; $5 \mathrm{~cm}$ wide $\times 45 \mathrm{~cm}$ high; equipped with 15-cm-high clear Plexiglas sidewalls) and two open arms (white Plexiglas; $5 \mathrm{~cm}$ wide $\times 45 \mathrm{~cm}$ high; no sidewalls) that were radiating from a central platform (white Plexiglas; $5 \mathrm{~cm}$ wide $\times 5 \mathrm{~cm}$ high) to form a plus sign. The entire platform was elevated to a height of $55 \mathrm{~cm}$ above the floor level under ambient conditions (300 lux). Each mouse was placed on the central platform facing one of the open arms, and the activities were recorded for $10 \mathrm{~min}$. The number of entries into open and closed arms, the stay time on the open and closed arms (seconds), and total distance traveled (centimeters) were automatically analyzed using Image EP software.

Porsolt forced swim test. The forced swim test was performed as described previously (Porsolt et al., 1977). A clear acrylic cylinder $(13 \mathrm{~cm}$ diameter $\times 30 \mathrm{~cm}$ high) was filled with water $\left(25^{\circ} \mathrm{C}\right)$ up to a height of 15 $\mathrm{cm}$. The cylinder was then transferred into a white acrylic box with a video camera attached above and illuminated at 30 lux. A mouse was placed in the cylinder, and its behavior was recorded for $10 \mathrm{~min}$. A mouse was judged to be immobile when it was making only minimal movements to keep its head above water. Immobile time (seconds) and freezing percentages were automatically analyzed by Image FZ software.

Fear conditioning. Fear conditioning was conducted in a conditioning chamber (transparent acrylic box; $25 \mathrm{~cm}$ wide $\times 33 \mathrm{~cm}$ high $\times 28 \mathrm{~cm}$ deep) equipped with electricity-conducting metal wires aligned at the bottom. The entire conditioning chamber was placed in a sound-proof box. On the first day, mice were placed in the conditioning chamber $(150$ lux; background noise at $50 \mathrm{~dB}$ ), and auditory stimuli (white noise at 55 $\mathrm{dB}$ for $30 \mathrm{~s})$ paired with electric footshocks $(0.2 \mathrm{~mA}$ for $2 \mathrm{~s}$; during the last $2 \mathrm{~s}$ of the auditory stimuli) were applied at 1,3 , and $5 \mathrm{~min}$ (indicating the onset of the tone). On the second day, mice were placed in the same conditioning chamber, and the activities were monitored. The mouse behavior during the first 2 min was used for the analysis of contextinduced fear. A pair of tone and footshock (same as day 1) was then delivered at $3 \mathrm{~min}$ (indicating the onset of the tone), and the test ended at $4 \mathrm{~min}$. On the third day, mice were transferred to a distinct chamber (white triangular acrylic box; $33 \mathrm{~cm}$ side $\times 32 \mathrm{~cm}$ high) under different conditions (illumination at 30 lux; background noise at $55 \mathrm{~dB}$; different odor and floor texture). During the 6 min test session, the conditioned stimulus (white noise at $60 \mathrm{~dB}$ for $120 \mathrm{~s}$ ) was applied between 2 and $4 \mathrm{~min}$ (in bins 3-4 on day 3 ). In each session, mouse behaviors were monitored with a video camera attached at the top of the chambers. Immobile time (seconds), freezing rate (percentage), and total distance traveled (centimeters) were automatically analyzed by Image FZ software.

Hot plate test. To measure thermal nociception in mice, a hot plate test was performed as described previously (Mogil et al., 1999). Briefly, 30week-old male mice were placed on a metal surface of a hot plate (TGK) maintained at $55.0 \pm 0.1^{\circ} \mathrm{C}$. A colorless transparent plastic cylinder $(23$ $\mathrm{cm}$ high $\times 16 \mathrm{~cm}$ diameter) was used to constrain the mice for behavioral observation. In this analysis, two behavioral responses were regarded as indicators of thermal nociception: hindpaw lick or hindpaw shake/flutter. We measured the latency (seconds) of thermal nociception. Mice were quickly removed from the hot plate right after the responses. Cutoff time for the test was $60 \mathrm{~s}$.

Basal activity. The basal locomotive activities in home cages were measured by counting the number of line-crossing (an infrared sensor-based electronic preset counter; Keyence) for $3 \mathrm{~d}$. The data from days 2 and 3 were used for the analysis for the total and nighttime activities. 
A in situ hybridization (6-week-old mice)

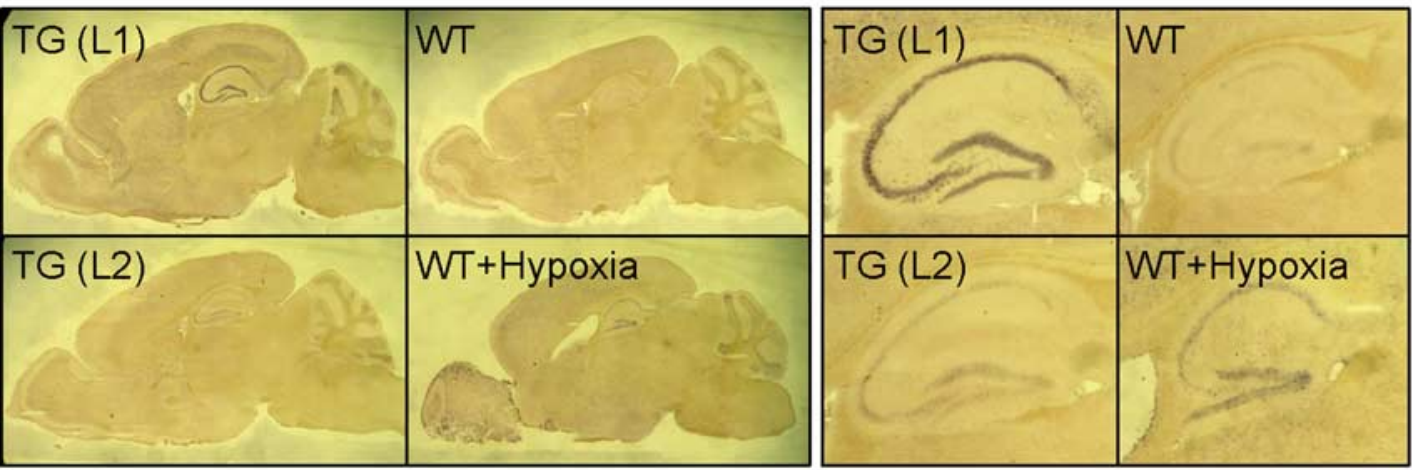

B Western blot (6-week-old mice) Total Brain

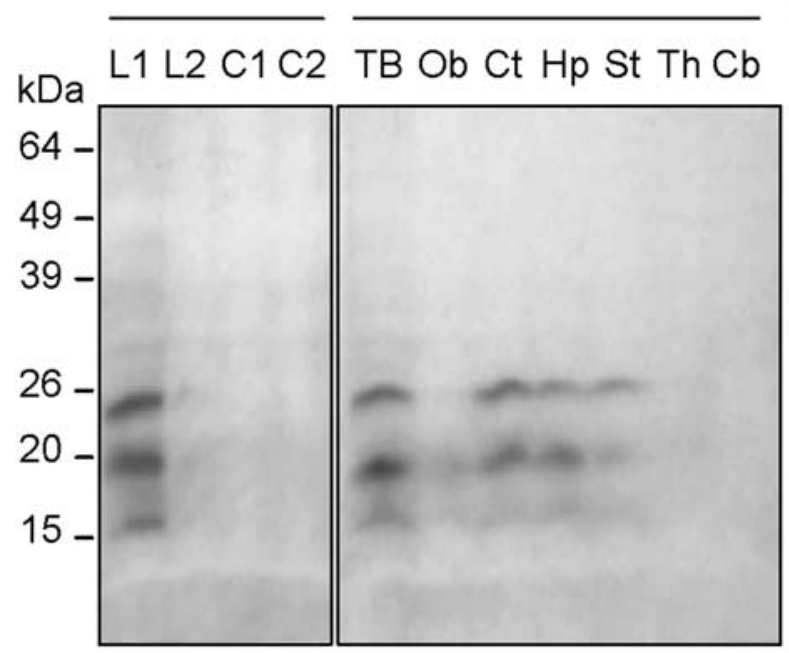

C Immunofluorescent staining 6-week-old mice Nuclei / VEGF

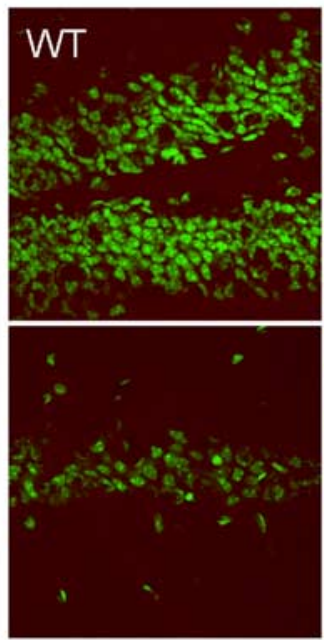

\section{Brain (6-week-old mice) $\mathrm{E}$ Brain/Body weight (15-week-old mice)}
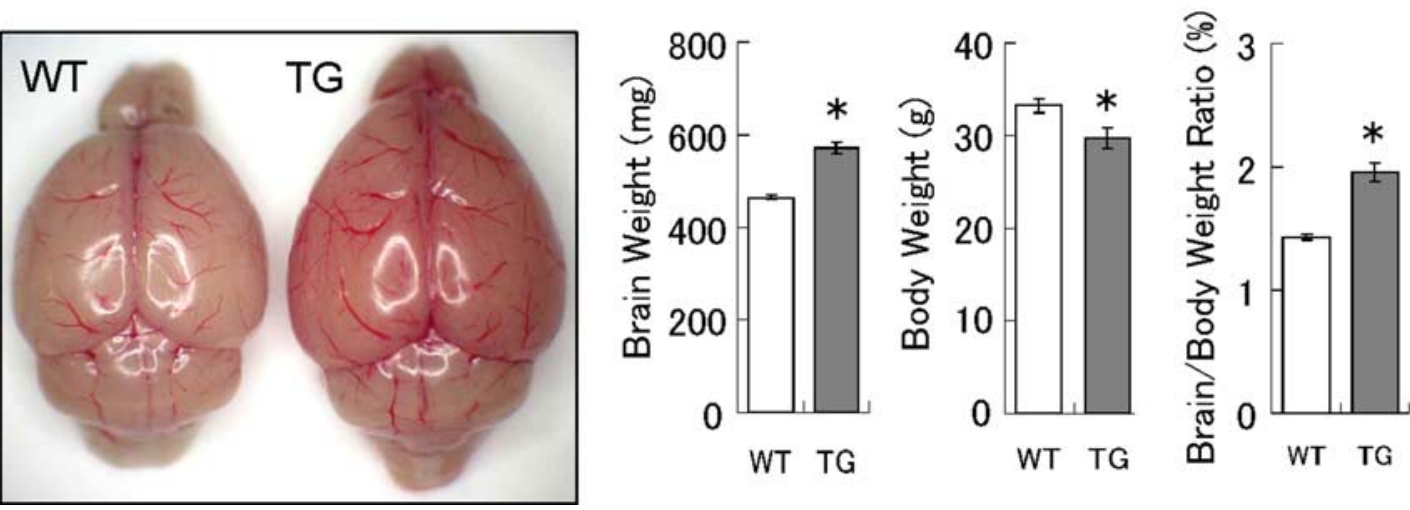

Figure 1. TG mice overexpressing VEGF120 under control of a CaMKIl $\alpha$ promoter. $A$, Expression of VEGF mRNA in forebrain. The sagittal brain sections from 6-week-old WT (control and hypoxia) and TG [line 1 (L1) and line 2 (L2)] mice were analyzed by in situ hybridization (left 4 panels). The magnified images of hippocampal regions were also presented (right 4 panels). As a reference, endogenous VEGF mRNAs in WT mice were induced by hypoxia. The purple-colored staining indicates the expression of VEGF mRNAs. $\boldsymbol{B}$, Expression of VEGF120 proteins. Protein extracts from whole brains of WT and TG mice (left; mice from lines 1 and 2) or different brain regions in line 1 TG mice (right) were analyzed by Western blot. Mature and precursor forms of VEGF120 (19 and 23 kDa, respectively; the 16 kDa band may represent an unglycosylated or degraded form) were detected in line 1 TG mice. VEGF120 was expressed in cortex, hippocampus, and striatum. L1 and C1, TG and WT mice in line 1; L2 and C2, TG and WT mice in line 2; TB, total brain; Ob, olfactory bulb; Ct, cerebral cortex; Hp, hippocampus; St, striatum; Th, thalamus; Cb, cerebellum. C, VEGF expression in hippocampal neurons. The areas of GCLs (top) and CA1 pyramidal cell layers (bottom) in 6-week-old WT (left) and TG (right) mice were analyzed by immunocytochemistry (green, nucleus; red, VEGF). Scale bar, $100 \mu \mathrm{m}$. DG, Dentate gyrus. D, Enlarged reddish brain in TG mice. The picture shows freshly isolated brains of 6-week-old WT (left) and TG (right) mice. $\boldsymbol{E}$, Brain and body weights. Graphs represent brain weights (milligrams), body weights (grams), and brain/body weight ratios (percentage) in 15-week-old male mice. $n=19$ and $15 .{ }^{*} p<0.01$, unpaired Student's t test. Data are as follows: brain weights: WT mice, $464.3 \pm 4.2 \mathrm{mg} ; \mathrm{TG}$ mice, $570.9 \pm 12.2 \mathrm{mg}$; body weights: WT mice, $33.2 \pm 0.8 \mathrm{~g} ; \mathrm{TG}$ mice, $29.7 \pm 1.1 \mathrm{~g}$; brain/body weight ratios: WT mice, $1.43 \pm 0.02 \% ; \mathrm{TG}$ mice, $1.95 \pm 0.08 \%$. 
Statistical analysis

All data for quantitative studies are expressed as mean \pm SEM and are described in the figure legends. Parametric analyses were performed with the unpaired Student's $t$ test or Welch's $t$ test for comparisons of two groups, or one- or two-way factorial or repeated-measure ANOVA for comparisons of more than two groups (multiple comparisons by TukeyKramer's or Scheffe's post hoc test, if applicable). Nonparametric analyses were performed with the Mann-Whitney $U$ test for comparisons of two groups or the Kruskal-Wallis test for comparisons of more than two groups (multiple comparisons by Steel-Dwass's or Scheffe's post hoc test, if applicable). A value of $p<0.05$ was considered to be significant.

\section{Results}

TG mice overexpressing VEGF120

To specify the VEGF receptor-mediated signaling, we have created TG mice overexpressing a short active variant of VEGF-A (mouse VEGF120) in forebrain under control of a CaMKII $\alpha$ promoter. This promoter drives gene expression in excitatory neurons in forebrain from 2 to 3 weeks after birth, minimizing potential side effects during development (Mayford et al., 1995). Two of four lines (lines 1 and 2) transmitted the transgene to the F1 generation, and they were backcrossed with C57BL/6.

We first examined the mRNAs by in situ hybridization (Fig. 1A). VEGF mRNA was found to be expressed in forebrain including hippocampus, cerebral cortex, and striatum in line 1 TG mice. However, expression in line 2 was comparable to that of WT mice. As a reference, endogenous VEGF mRNAs were induced by hypoxia in WT mice, which showed increased expression in broad regions including pyramidal and GCLs in hippocampus. Western blot analysis of protein extracts showed similar results that the level of VEGF120 was higher in hippocampus, cerebral cortex, and striatum in line 1 (Fig. $1 B$ ). In contrast, VEGF expression in line 2 was similar to that of WT controls. Therefore, we used line 1 for additional studies. The protein concentration of VEGF as determined by ELISA showed a $\sim 25$-fold increase in cerebral cortex and hippocampus in TG mice $(\sim 80$ and $\sim 2000 \mathrm{pg} / \mathrm{mg}$ tissue for WT and TG mice; data not shown). At a cellular level, the expression of VEGF120 was evident in the cytoplasmic compartments of cell bodies and proximal dendrites of both granule and pyramidal cells in hippocampus (Fig. 1C).

When brains were isolated, it was apparent that TG mice had an enlarged reddish forebrain with distinct vascular struc-
A Cell staining (6-week-old mice)

B Cell density (6-week-old mice)
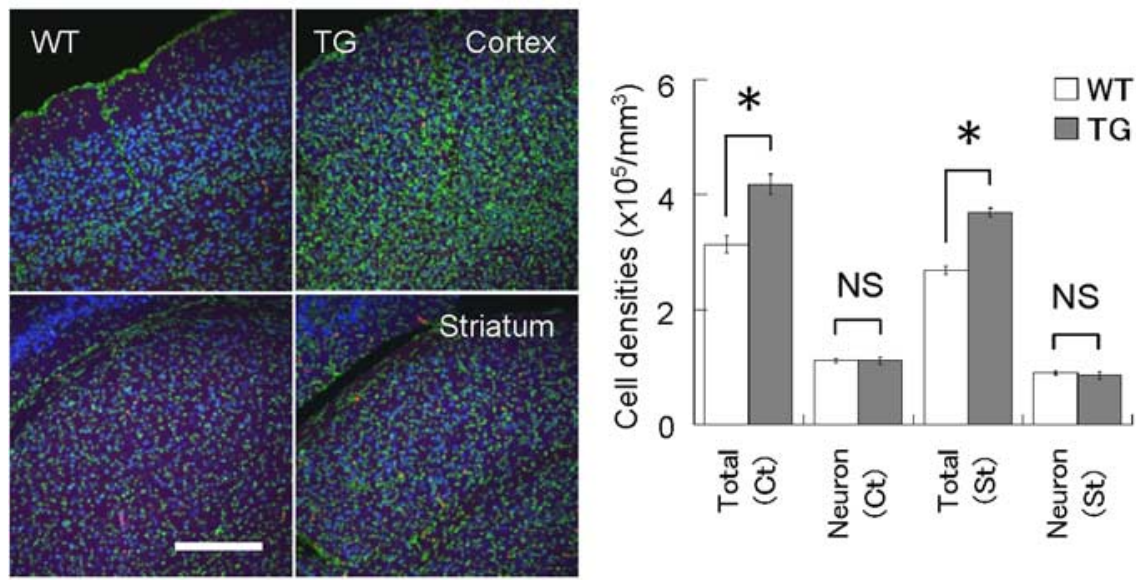

C BrdU-labeling (6-week-old mice)
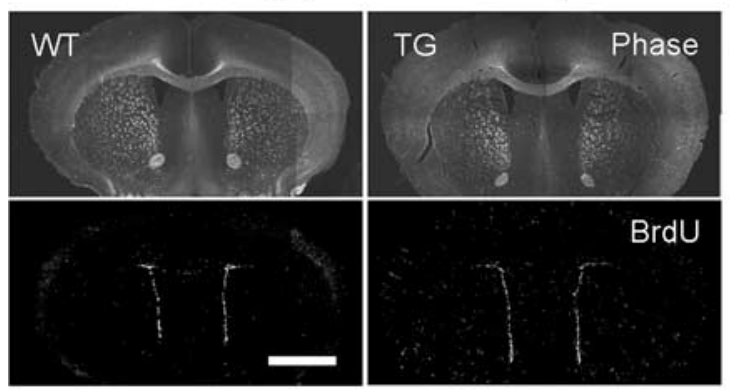

D Cell proliferation (6-week-old mice)

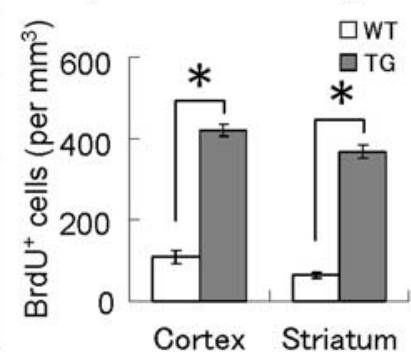

\section{E Lectin staining}
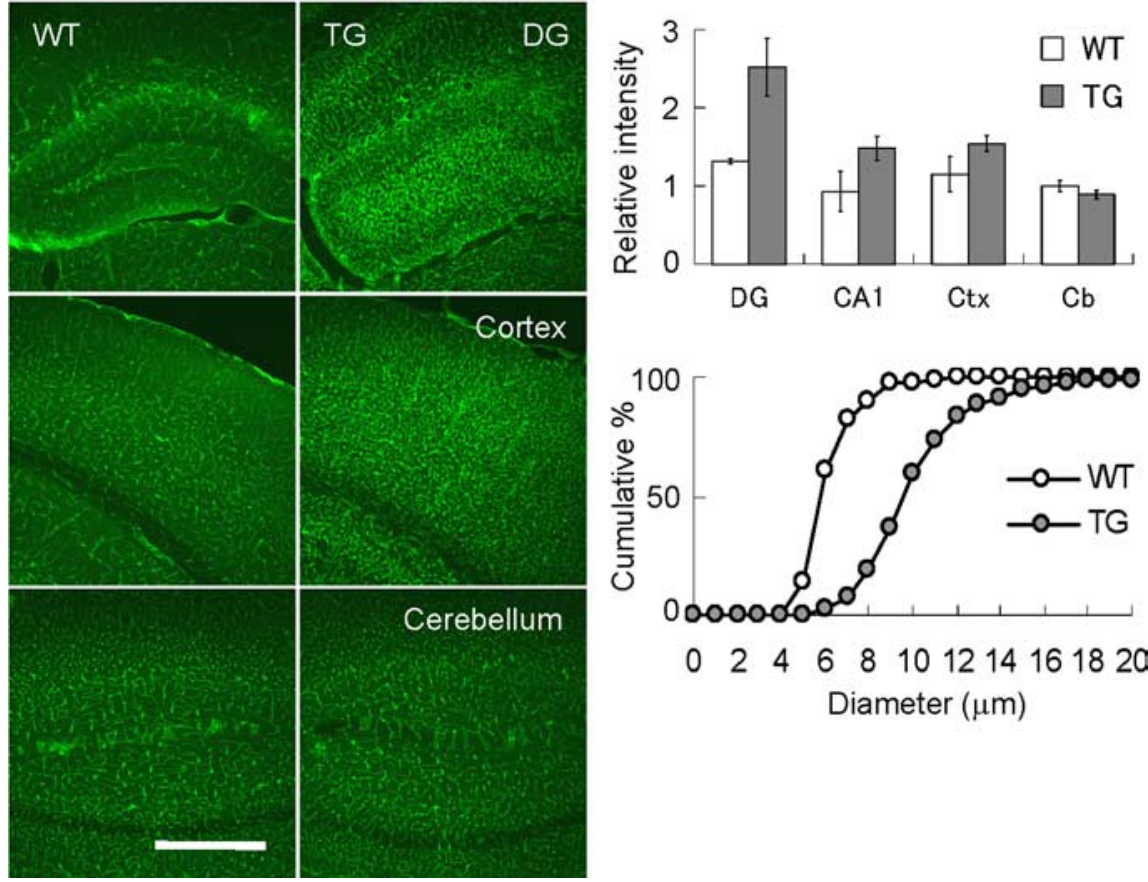

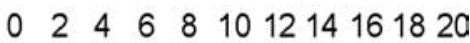
Diameter $(\mu \mathrm{m})$

Figure 2. Enhanced cell proliferation and angiogenesis in VEGF120-TG mice. A, Increased cell population in forebrain. Coronal brain sections of 6-week-old WT (left) and TG (right) mice were stained for cell nuclei (green, Syto13 green) and neurons (blue, NeuN as a neuronal marker). Images of cerebral cortex (top) and striatum (bottom) are shown. There are more nuclei in the brain sections of TG mice. $\boldsymbol{B}$, Cell densities in cerebral cortex and striatum. The total cell density was increased by $30 \%$ in TG mice, whereas the neuronal density was similar (although the total neuronal population might be increased because of the enlargement of brain). $n=8$ per group, 6-week-old mice; ${ }^{*} p<0.01$ and nonsignificant (NS), one-way ANOVA followed by Tukey-Kramer's post hoc test. Data are as follows: total cortical cells: WT mice, $3.13 \pm 0.14 \times 10^{5}$ cells $/ \mathrm{mm}^{3}$; (Figure legend continues.) 
tures (Fig. 1D). The weight of whole brains was increased by $\sim 20 \%$ in TG mice (brain weights: WT mice, $464.3 \pm 4.2 \mathrm{mg}$; TG mice, $570.9 \pm 12.2 \mathrm{mg} ; n=19 \mathrm{WT}$ and $15 \mathrm{TG}, 15$-week-old mice; $p<0.01$, unpaired Student's $t$ test) (Fig. $1 E$ ). In contrast, the body size of TG mice was rather small (body weights: WT mice, $33.2 \pm 0.8 \mathrm{~g}$; TG mice, $29.7 \pm 1.1 \mathrm{~g} ; n=19 \mathrm{WT}$ and $15 \mathrm{TG}$, 15-week-old mice; $p<0.01$, unpaired Student's $t$ test), which resulted in a $37 \%$ increase in the brain/body weight ratio (brain/ body weight ratios: WT mice, $1.43 \pm 0.02 \%$; TG mice, $1.95 \pm$ $0.08 \% ; n=19 \mathrm{WT}$ and $15 \mathrm{TG}, 15$-week-old mice; $p<0.01$, unpaired Student's $t$ test). Based on the fact that the onset of VEGF120 expression is 2 weeks after birth (supplemental Fig. 1, available at www.jneurosci.org as supplemental material), these results suggest that VEGF enhances postnatal brain development, to some extent.

\section{Increased cell proliferation and angiogenesis in forebrain}

To investigate the cellular changes in forebrain, brain sections from cerebral cortex and striatum were double stained for cell nuclei (Syto13 green) and neurons (NeuN as a marker) (Fig. 2A). We counted the number of nuclei and NeuN-positive cells and found that the cell densities in forebrain including cerebral cortex and striatum were increased by $>30 \%$ in TG mice (genotype effect for total cell densities: $F_{(1,28)}=72.60, p<0.0001$; no interaction effect; two-way factorial ANOVA; $n=8$ per group, 6-week-old mice). However, the analysis of NeuN-positive cells in cerebral cortex and striatum indicated that there was no difference in the neuronal densities between WT and TG mice (genotype effect for neuronal densities: $F_{(1,28)}=0.18, p=0.67$; no interaction effect; two-way factorial ANOVA; $n=8$ per group, 6-week-old mice), although an enlargement of forebrain might have resulted in an increase in the total neuronal population (Fig. $2 B$ ). To examine cell genesis, dividing cells were specifically labeled in vivo with $\mathrm{BrdU}(100 \mathrm{mg} / \mathrm{kg}$, i.p.). It was found that the distribution pattern of BrdU-positive cells in forebrain was sim-

\footnotetext{
(Figure legend continued.) TG mice, $4.18 \pm 0.16 \times 10^{5}$ cells $/ \mathrm{mm}^{3}$; cortical neurons: WT mice, $1.12 \pm 0.03 \times 10^{5}$ cells $/ \mathrm{mm}^{3} ; \mathrm{TG}$ mice, $1.12 \pm 0.06 \times 10^{5} \mathrm{cells} / \mathrm{mm}^{3}$; total striatal cells: WT mice, $2.81 \pm 0.02 \times 10^{5}$ cells $/ \mathrm{mm}^{3} ; \mathrm{TG}$ mice, $3.69 \pm 0.07 \times 10^{5}$ cells $/ \mathrm{mm}^{3}$; striatal neurons: WT mice, $0.90 \pm 0.03 \times 10^{5}$ cells $/ \mathrm{mm}^{3}$; TG mice, $0.86 \pm 0.06 \times 10^{5}$ cells $/ \mathrm{mm}^{3}$. C, Distribution of dividing cells in forebrain. Proliferating cells in 6-week-old WT (left) and TG (right) mice were labeled with BrdU for $2 \mathrm{~h}$. Coronal brain sections at cortex/striatum positions were presented as phase-contrast images (top) and BrdU immunofluorescent images (bottom; white dots represent BrdU-positive cells). $\boldsymbol{D}$, Density of proliferating cells in cerebral cortex and striatum. The graph indicates the densities of BrdU-positive cells in cerebral cortex and striatum. $n=3$ per group, 6 -week-old mice. ${ }^{*} p<0.01$, one-way ANOVA followed by Tukey-Kramer's post hoc test. Data are as follows: cortical BrdU-positive cells: WT mice, $109 \pm 16 \mathrm{cell} / \mathrm{s} / \mathrm{mm}^{3}$; TG mice, $420 \pm 15$ cells $/ \mathrm{mm}^{3}$; striatal BrdU-positive cells: WT mice, $65 \pm 7$ cells $/ \mathrm{mm}^{3} ; \mathrm{TG}$ mice, $368 \pm 16 \mathrm{cells} / \mathrm{mm}^{3}$. E, Enhanced angiogenesis. Blood vessels were visualized by staining with L. esculentum (tomato) lectin. Representative images of dentate gyrus (DG; top), cerebral cortex (middle), and cerebellum (bottom) in 6-week-old WT (left) and TG (right) mice are shown. $\boldsymbol{F}_{\text {, }}$ Quantitative analysis of blood vessels. The bar graph (top) indicates the relative fluorescent intensities of the lectin staining in dentate gyrus (DG), CA1 region (CA1), cerebral cortex (Ctx), and cerebellum $(\mathrm{Cb})$. The values were normalized to the signal intensity in cerebellum of WT mice (set to 1). $n=2-3$ per group, 6 -week-old mice; $p<0.01$ for dentate gyrus and nonsignificant for cerebellum in TG mice, one-way factorial ANOVA followed by Tukey-Kramer's post hoc test. Data for normalized lectin intensities are as follows: dentate gyrus: WT mice, $1.31 \pm$ 0.02; TG mice, 2.52 \pm 0.22 ; CA1: WT mice, $0.93 \pm 0.18$; TG mice, $1.48 \pm 0.19$; cerebral cortex: WT mice, $1.15 \pm 0.16$; TG mice, $1.54 \pm 0.19$; cerebellum: WT mice, $1.00 \pm 0.05$; TG mice, $0.89 \pm 0.05$. The cumulative plot (bottom) indicates capillary diameters (lengths of the minor axes) in polymorphic regions of dentate gyrus in WT (open circle) and TG (filled circle) mice. $n=$ 200 capillaries from 3 mice per group, 6-week-old mice. $p<0.0001$, unpaired Student's $t$ test. Data are as follows: capillary diameters: WT mice, $6.1 \pm 0.1 \mu \mathrm{m}$; TG mice, $10.2 \pm 0.2 \mu \mathrm{m}$. Scale bars: $A, 200 \mu \mathrm{m} ; \boldsymbol{C}, 2 \mathrm{~mm} ; \boldsymbol{E}, 500 \mu \mathrm{m}$.
}

ilar between genotypes, where many BrdU-positive cells were localized in ependyma of lateral ventricle, external capsule, and dentate gyrus of hippocampus (Fig. 2C). In general, cell divisions are less frequent in cerebral cortex and striatum, but TG mice showed a robust threefold to fivefold increase in BrdU-positive cells in these regions (genotype effect: $F_{(1,8)}=215.32, p<0.0001$; no interaction effect; two-way factorial ANOVA; $n=3$ per group, 6-week-old mice) (Fig. 2D). Many of these BrdU-labeled cells in cerebral cortex and striatum had smaller $(\sim 5 \mu \mathrm{m})$ oval-shaped nuclei and were often found along vascular-like structures, suggesting that many of these proliferating cells are VECs, one of the major targets of VEGF.

To visualize the blood vessels, brain slices were stained with $L$. esculentum (tomato) lectin (Thurston et al., 1996) (Fig. 2E). As expected, vascular development was evident in the TG mice. Angiogenesis was significant in dentate gyrus, whereas there was no difference in cerebellum where the CaMKII $\alpha$ promoter is almost quiescent (normalized intensities: $p<0.01$ for dentate gyrus and nonsignificant for cerebellum; one-way factorial ANOVA followed by Tukey-Kramer's post hoc test; $n=2-3$ per group, 6-week-old mice) (Fig. 2F, top). The diameter of capillaries in polymorphic regions of dentate gyrus was also increased in TG mice (capillary diameter: WT mice, $6.1 \pm 0.1 \mu \mathrm{m}$; TG mice, $10.2 \pm 0.2 \mu \mathrm{m} ; n=200$ capillaries from three mice per group, 6-week-old mice; $p<0.0001$, unpaired Student's $t$ test) (Fig. 2 F, bottom). The density of actively dividing VECs was doubled in dentate gyrus of TG mice (BrdU-positive VECs: WT mice, $6.02 \pm$ 0.98 cells $/ \mathrm{mm}^{3}$; TG mice, $11.35 \pm 0.75 \times 10^{3}$ cells $/ \mathrm{mm}^{3} ; n=8$ per group, 6-week-old mice; $p<0.001$, unpaired Student's $t$ test). These results suggest that VEGF120 significantly enhances angiogenesis in forebrain.

VEGF is a secreted factor so that it can diffuse into other areas. However, the physiological effect of VEGF120 (as judged by angiogenesis) was mostly restricted to forebrain. We also found no increase in the serum concentration of VEGF (examined by ELISA; data not shown), suggesting that overexpression of VEGF120 in forebrain does not affect the rest of the body.

\section{Cell proliferation in dentate gyrus}

To examine the morphology of hippocampus, isolated hippocampi were sliced from dorsal to ventral direction at $250 \mu \mathrm{m}$ intervals and stained for cell nuclei (Fig. 3A). We found that gross anatomical structures were similar between WT and TG mice, but we noticed an expansion of the GCL and enlargement of hippocampus in TG mice. Quantitative analysis indicated that the volume of GCL and hippocampus (excluding fimbria and subiculum) was significantly increased by 57 and 24\%, respectively (GCL volume: WT mice, $0.46 \pm 0.02 \mathrm{~mm}^{3}$; TG mice, $0.72 \pm 0.03 \mathrm{~mm}^{3}$; hippocampal volume: WT mice, $12.53 \pm 0.23$ $\mathrm{mm}^{3}$; TG mice, $15.49 \pm 0.28 \mathrm{~mm}^{3} ; n=4$ per group, 6 -week-old mice; $p<0.001$, unpaired Student's $t$ test) (Fig. $3 B, C$ ). These results suggest that vigorous cell genesis and/or angiogenesis have resulted in an enlargement of hippocampus.

Cell proliferation in hippocampus was examined by the in vivo labeling with BrdU in 6-week-old mice. Many BrdU-positive cells were identified in SGZ of dentate gyrus, where NPCs are especially enriched (Fig. 3D). We counted the number of BrdUpositive cells and found that the density of proliferating cells in SGZ was almost doubled in TG mice (BrdU-positive cell densities; WT mice, $4.98 \pm 0.58$ cells/mm SGZ; TG mice, $10.47 \pm 1.63$ cells/mm SGZ; $n=10$ per group, 6-week-old mice; $p<0.01$, Welch's $t$ test). Thus, overexpression of VEGF120 indeed stimulated cell proliferation of NPCs in hippocampus. 


\section{A Hippocampus (6-week-old mice)}
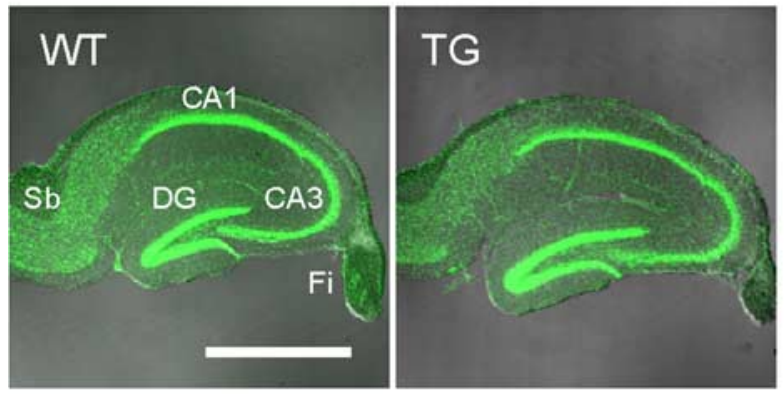

\section{B Area (6-week-old mice)}

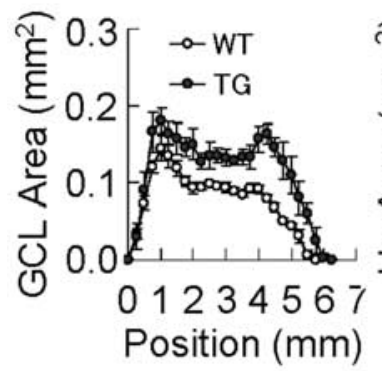

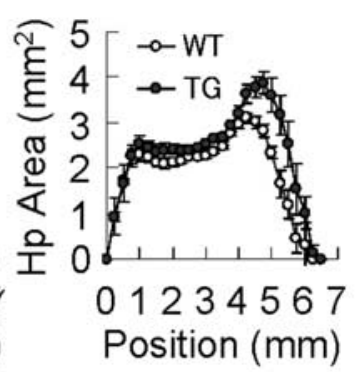

C Volume (6-week-old mice)

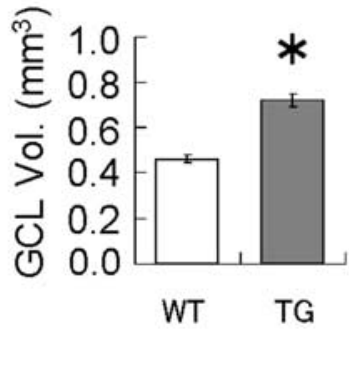

\section{BrdU-labeling (6-week-old mice)}

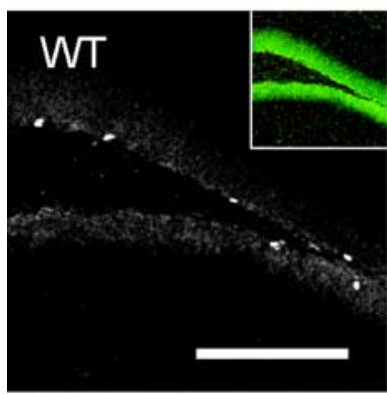

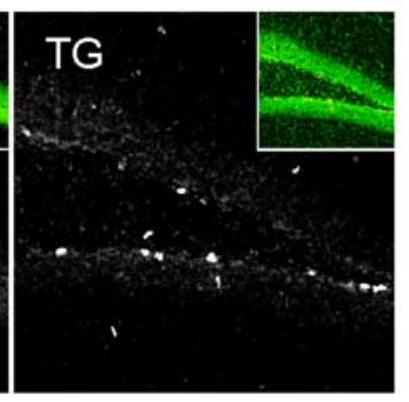

E Running wheel exercise (6-week-old mice)

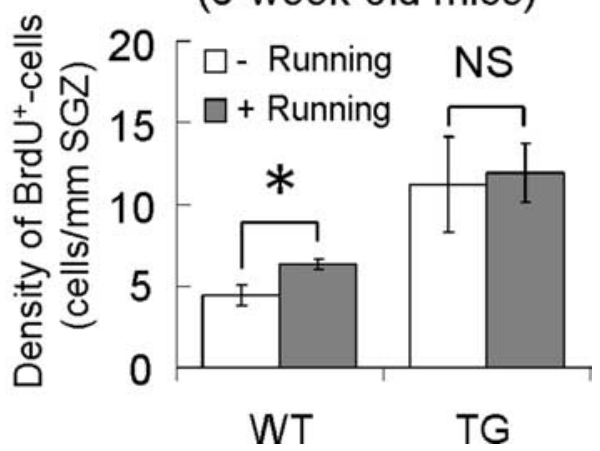

Figure 3. Hippocampal cell genesis in VEGF120-TG mice. $A$, Increased volume of GCL and hippocampus. The pictures represent the merged images of phase-contrast (grayscale) and nuclear (green) staining of hippocampal slices from 6-week-old WT (left) and TG (right) mice. DG, Dentate gyrus; Sb, subiculum; Fi, fimbria. B, Cross-sectioned areas (in mm ${ }^{2}$ ) of GCL (left) and hippocampus (right; Hp). Hippocampi from WT (open circle) and TG (filled circle) mice were sliced (50 $\mu \mathrm{m}$ thickness) from the dorsal to ventral direction at $250 \mu \mathrm{m}$ intervals, and the cross-sectioned areas were measured. $n=4$ hippocampi per group, 6-week-old mice. C, Volumes (Vol.; i $\mathrm{mm}^{3}$ ) of GCL and hippocampus (Hp). $n=4$ hippocampi per group, 6-week-old mice. ${ }^{*} p<0.001$, unpaired Student's $t$ test. Data are as follows: $\mathrm{GCL}$ volume: WT mice, $0.460 \pm 0.015 \mathrm{~mm}^{3}$; TG mice, $0.721 \pm 0.026 \mathrm{~mm}^{3}$; hippocampal volume:WT mice, $12.526 \pm 0.233 \mathrm{~mm}^{3} ;$ TG mice, $15.491 \pm 0.284 \mathrm{~mm}^{3}$. D. Cell proliferation in dentate gyrus. Dividing cells in 6-week-old mice were labeled with BrdU for $2 \mathrm{~h}$ in vivo, and regions of dentate gyrus were examined. Most of the BrdU-positive cells were found in SGZ. Insets are nuclear staining of the presented images. The linear density of BrdU-positive cells along SGZ (cells/mm SGZ) was almost doubled in TG mice (BrdU-positive cell densities: WT mice, $4.98 \pm 0.58$ cells/mm SGZ; TG mice, $10.47 \pm 1.63$ cells/mm SGZ; $n=10$ per group, 6-week-old mice; $p<0.01$, Welch's $t$ test). E, Saturated level of cell proliferation in dentate gyrus of TG mice. The voluntary running-wheel exercise for 3 weeks (between 3 and 6 weeks of age) significantly enhanced cell proliferation in dentate gyrus by $>40 \%$ in WT mice, but no further enhancement was achieved in TG mice. Moreover, the level of cell proliferation in TG mice was found to be much higher than that of exercised WT mice. $n=6$ and 7 for WT controls and runners; $n=6$ and 5 for TG controls and runners; 6 -week-old mice. ${ }^{*} p<0.01$ and nonsignificant (NS; $p=0.83$ ), unpaired Student's $t$ test; $p<0.01$, Kruskal-Wallis test for all groups. Data are as follows: WT controls, $4.43 \pm 0.57$ cells $/ \mathrm{mm} \mathrm{SGZ;} \mathrm{WT} \mathrm{runners,} 6.35 \pm 0.29$ cells/mm SGZ; TG controls, $11.20 \pm 2.67$ cells/mm SGZ; TG runners, $11.93 \pm 1.65$ cells/mm SGZ. Scale bars: $\boldsymbol{A}, 1 \mathrm{~mm} ; \boldsymbol{D}, 200 \mu \mathrm{m}$.

To evaluate the level of enhancement, we attempted to further stimulate the cell division of NPCs by the running-wheel exercise, voluntary exercise for rodents known to efficiently enhance hippocampal neurogenesis (van Praag et al., 1999; Kitamura et al., 2003) (Fig. 3E). The running-wheel exercise for 3 weeks (between 3 and 6 weeks old) significantly enhanced the BrdU incorporation by $>40 \%$ in WT mice (WT controls, $4.43 \pm 0.57$ cells $/ \mathrm{mm}$ SGZ; WT runners, $6.35 \pm 0.29$ cells $/ \mathrm{mm} \mathrm{SGZ;} n=6$ and 7 , 6 -week-old mice; $p<0.01$, unpaired Student's $t$ test), whereas no significant enhancement was observed in TG mice (TG controls, $11.20 \pm 2.67$ cells $/ \mathrm{mm}$ SGZ; TG runners, $11.93 \pm 1.65$ cells $/ \mathrm{mm}$ SGZ; $n=6$ and 5, 6-week-old mice; $p=0.83$, unpaired Student's $t$ test). The level of cell proliferation in TG mice turned out to be much higher than that of WT mice with exercise $(p<0.01$, Kruskal-Wallis test for all groups and Mann-Whitney $U$ test between exercised WT mice and control TG mice). This result suggests that the rate of cell divisions in SGZ may be at nearsaturation in TG mice. Therefore, a short active variant of 
VEGF-A (i.e., activation of Flk-1 or Flt-1) sufficiently enhances cell division of NPCs in adult hippocampus. In this analysis, we also found in WT mice that $\sim 60 \%$ of BrdU-positive cells were localized near capillaries in SGZ and that the running-wheel exercise increased cell proliferation near capillaries (the percentages of BrdU-positive cells along capillaries in controls and runners were $59.2 \pm 1.8$ and $70.0 \pm 1.3 \%$, respectively; $n=6$ and 5 per group, 6-week-old WT mice; $p<0.01$, unpaired Student's $t$ test; examined by the nucleus/BrdU/lectin triple staining). Thus, cell proliferation of NPCs or VECs along capillaries is preferentially stimulated by voluntary exercise.

\section{VEGF enhances neurogenesis but does not affect cell differentiation in dentate gyrus}

To visualize NPCs in dentate gyrus, brain sections were immunostained for Nestin (Lendahl et al., 1990) (Fig. 4A). The Nestin immunoreactions were apparently stronger in TG mice. Nestinpositive cells are often found along SGZ in WT mice, whereas they are also detected in the polymorphic regions between the blades of GCL in TG mice. Consistently, Western blot analysis showed a marked increase of Nestin in TG mice (Fig. 4B).

We next examined the immature neurons using Dcx (Francis et al., 1999) (Fig. 4C). Immunostaining of Dcx revealed the cell morphology of immature neurons in GCL. Dcx signals were also found to be stronger in TG mice, and the dendritic arbor of immature neurons appeared to be more developed in TG mice (see supplemental Fig. 2, available at www.jneurosci.org as supplemental material, for enlarged images). Usually, Dcx-positive immature neurons are localized in the innermost layer of GCL. However, many of these cells were inserted into the middle or even outer layer of GCL in TG mice. Similarly, most of the 4-week-old young neurons (BrdU/NeuN double-positive cells) in WT mice were localized in the inner layer of GCL. In contrast, many young neurons were found in the middle or outer layer of GCL in TG mice (see supplemental Fig. 3, available at www. jneurosci.org as supplemental material, for enlarged images).

To evaluate the effects of VEGF on cell differentiation, we examined the cell types of newborn cells in GCL. Proliferating cells in 6-week-old mice were labeled with BrdU and examined after 4 weeks (newborn cells were allowed to differentiate for 4 weeks). The brain sections were triple stained for BrdU, NeuN (neuronal marker), and GFAP (astrocyte marker), and doublepositive cells $\left(\mathrm{BrdU}^{+} / \mathrm{NeuN}^{+}\right.$- or $\mathrm{BrdU}^{+} / \mathrm{GFAP}^{+}$-positive cells) in GCL were counted (Fig. $4 D$ ). The percentages of neurons or astrocytes among BrdU-labeled cells in GCL were found to be similar between WT and TG mice (neurons: WT mice, $80.2 \pm$ 2.3\%; TG mice, $76.5 \pm 2.9 \%$; astrocytes: WT mice, $0.6 \pm 0.5 \%$; TG mice, $0.5 \pm 0.3 \%$; other cell types: WT mice, $19.2 \pm 2.1 \%$; TG mice, $23.0 \pm 3.0 \% ; n=16$ slices from four mice per group, 10 -week-old mice; no significant differences in neurons, astrocytes, or other cell types between WT and TG mice by SteelDwass's test) (Fig. 4E). Therefore, most of the newborn cells in GCL are indeed differentiated into neurons ( $\sim 80 \%$; note that the actual percentage may be higher because not all BrdU-positive cells in GCL were derived from NPCs). Because NPCs in SGZ have been shown to generate neurons and astrocytes (Gage et al., 1995), this result suggests that VEGF does not modulate the differentiation of newborn cells derived from NPCs in dentate gyrus. In this analysis, we also found that the number of 4-weeksurvived BrdU-positive cells in GCL was doubled in TG mice (4-week-old BrdU-positive cells in GCL: WT mice, $4.58 \pm 0.24$ cells $/ \mathrm{mm}^{3}$; TG mice, $9.78 \pm 1.17 \times 10^{3}$ cells $/ \mathrm{mm}^{3} ; n=4$ per group, 10 -week-old mice; $p<0.001$, Welch's $t$ test). This is in good agreement with the result from the short-term BrdU administration (Fig. 3D). Together, these data indicate that VEGF exerts a strong neurogenic effect in adult hippocampus.

\section{VEGF alone is not sufficient for long-term enhancement of adult neurogenesis}

We speculated that if VEGF directly promotes proliferation of NPCs, a considerable number of dividing cells would be detected even in aged animals. To test this hypothesis, we labeled the proliferating cells with BrdU for $2 \mathrm{~h}$ at different ages $(3,6,10,20$, and 50 weeks after birth) and compared the densities of BrdUpositive cells along SGZ (Fig. 5A). We found that the cell proliferation in SGZ was markedly promoted by VEGF120 at 3-10 weeks after birth, which confirmed our previous observations ( 3 weeks old: WT mice, $15.50 \pm 1.43$ cells $/ \mathrm{mm}$ SGZ; TG mice, $30.65 \pm 8.02$ cells/mm SGZ; $n=9$ per group; $p<0.05$, MannWhitney $U$ test; 6 weeks old: WT mice, $4.98 \pm 0.58$ cells $/ \mathrm{mm}$ SGZ; TG mice, $10.47 \pm 1.63$ cells/mm SGZ; $n=10$ per group; $p<$ 0.01 , Welch's $t$ test; 10 weeks old: WT mice, $4.74 \pm 0.46$ cells $/ \mathrm{mm}$ SGZ; TG mice, $8.70 \pm 1.48$ cells/mm SGZ; $n=7$ per group; $p<$ 0.05 , Welch's $t$ test) (Fig. $5 B$ ). However, the rate of cell genesis in TG mice rapidly declined with age and reduced to the control levels by 20 weeks of age (WT mice, $2.51 \pm 0.20$ cells $/ \mathrm{mm}$ SGZ; TG mice, $2.24 \pm 0.81$ cells $/ \mathrm{mm} \mathrm{SGZ;} n=6$ per group; $p=0.11$, Mann-Whitney $U$ test). At 50 weeks old, a minimal level of cell proliferation was observed in both groups (WT mice, $0.68 \pm 0.19$ cells/mm SGZ; TG mice, $0.96 \pm 0.34$ cells/mm SGZ; $n=4$ per group; $p=0.50$, unpaired Student's $t$ test) (Fig. $5 B$ ). This result suggests that cell proliferation of NPCs in dentate gyrus declines in a time-dependent manner in both WT and TG mice (Kuhn et al., 1996).

We wondered whether a failure to stimulate cell division of NPCs in older TG mice might be attributable to a reduction in VEGF120 expression. However, Western blot analysis of hippocampal extracts indicated that the level of VEGF120 was similar at 6, 10, 30, and 50 weeks of age in TG mice (Fig. 5C). In addition, VEGF mRNAs were still abundant in hippocampus at 30 weeks of age (in situ hybridization; data not shown). Thus, the declined cell proliferation in older TG mice was not the result of reduced expression of VEGF120. We also found that Flk-1 (VEGF receptor 2) is constantly expressed in hippocampus (Fig. $5 C$ ), suggesting that the downregulation of Flk-1 may not be the case. In contrast, BDNF and Nestin tended to decrease with age (see supplemental Fig. 4, available at www.jneurosci.org as supplemental material, for quantitative analysis). Interestingly, Nestin expression was still higher at 50 weeks of age, implying that a large population of NPCs may be quiescent in older TG mice. These results suggest that in addition to VEGF, the other factor(s) may be required to stimulate the cell division of NPCs in older mice. Although VEGF is a potent neurogenic factor, VEGF alone is not sufficient to support adult neurogenesis for prolonged periods.

\section{Anxiolytic-like effects of VEGF}

To investigate the effects of VEGF120 on affective behavior, we first examined the anxiety-related behavior in an open-field test (Fig. 6A). In a bright open field, mice tend to stay in the peripheral area by the enclosure and spend less time in the center area (or unprotected area). When mice were placed in the open field, TG mice spent more time in the center area than WT mice (time in center: WT mice, $86.6 \pm 6.7 \mathrm{~s}$; TG mice, $124.3 \pm 15.9 \mathrm{~s} ; n=19$ and 18, 10-week-old mice; $p<0.05$, unpaired Student's $t$ test), although the total distance traveled during the $10 \mathrm{~min}$ test period 

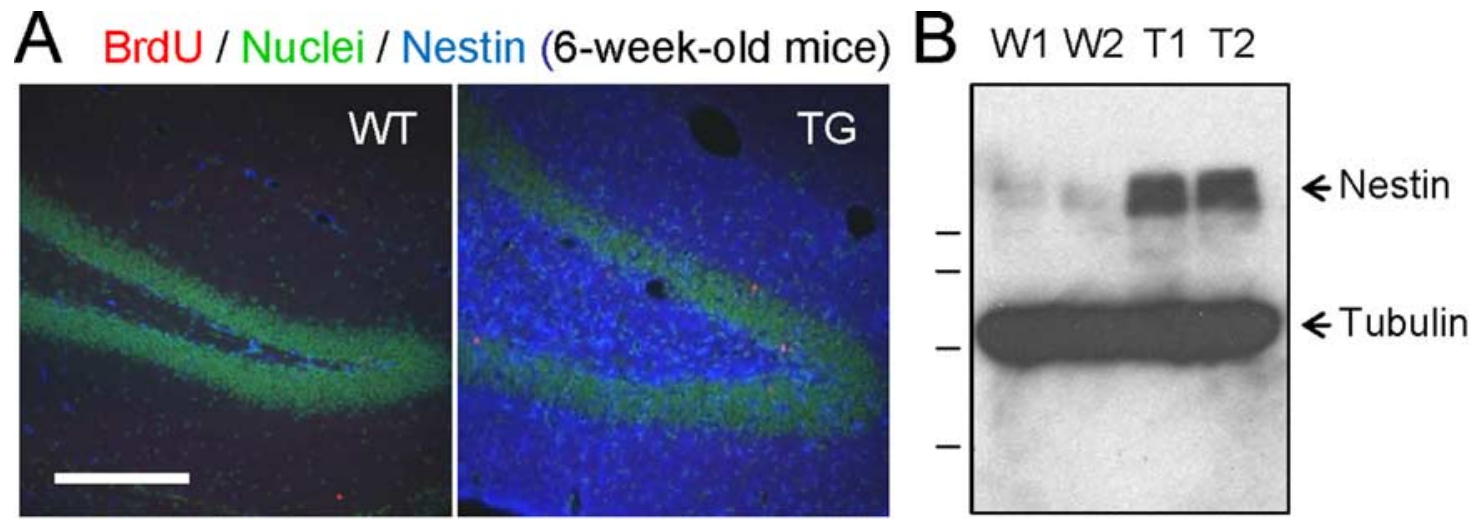

\section{BrdU/Dcx/ NeuN (10-week-old mice)}

\section{$\mathrm{BrdU} / \mathrm{NeuN}$}
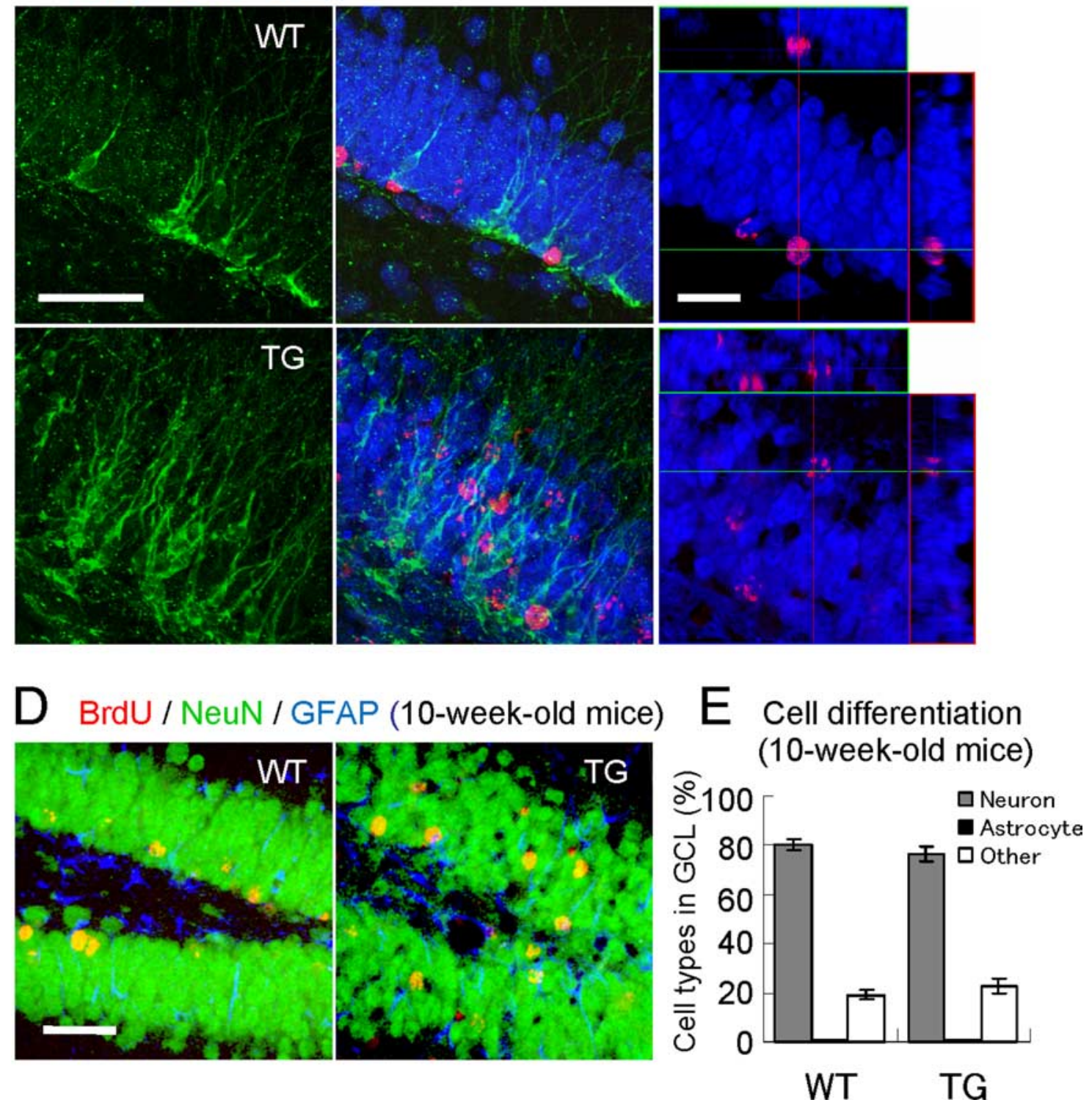

Figure 4. Enhanced hippocampal neurogenesis in VEGF120-TG mice. A, Nestin staining. Immunofluorescent images of Nestin (blue) and nuclei (green) in WT (left) and TG (right) mice showed intense signals of NPCs and/or immature neurons in TG mice. $\boldsymbol{B}$, Increased expression of Nestin. Western blot analysis of hippocampal extracts showed increased protein expression of Nestin (140 KDa) in TG mice (two mice per genotype: W1 and W2 for WT mice; T1 and T2 for TG mice; 6 -week-old mice). $\beta$-Tubulin was used as an internal control (51 kDa). Molecular weight standards are 103, 77,50 , and $34 \mathrm{kDa}$. C, Dcx staining. Mice were labeled with BrdU at 6 weeks of age and examined at 10 weeks of age. Brain sections were triple stained to identify immature neurons (green, Dcx), neurons (blue, NeuN), and 4-week-survived young cells (red, BrdU). The left four panels represent Dcx staining, and merged images of GCL in WT (top panels) and TG (bottom panels) mice. See also Dcx-stained images in supplemental Figure 2 (available at www.jneurosci.org as supplemental material). The right panels represent orthographic images of BrdU/NeuN-double positive cells in WT (top) and TG (bottom) mice. See also enlarged images in supplemental Figure 3 (available at www.jneurosci.org as supplemental material). In WT mice, most of the (Figure legend continues.) 
was similar (total distance: WT mice, $3675 \pm 152 \mathrm{~cm}$; TG mice, $3302 \pm 249 \mathrm{~cm} ; n=19$ and 18, 10-week-old mice; $p=0.38$, unpaired Student's $t$ test). This result suggests that TG mice have reduced anxiety-like behavior.

Anxiety-like behavior was also analyzed in the elevated plus maze (Fig. $6 B$ ). When mice are placed onto an elevated platform to induce natural aversion to height and open space, mice tend to stay within closed arms (safe area, equipped with sidewalls) and spend less time on open arms (risky area, without sidewalls). We found that TG mice more often explored open arms than WT controls (time on open arms: WT mice, $3.63 \pm 1.2 \%$; TG mice, $24.2 \pm 4.9 \% ; n=18$ and 15, 10 -week-old mice; $p<0.0001$, Mann-Whitney $U$ test), whereas the total distance traveled during the 10 min test period did not change (total distance: WT mice, $1583 \pm 82 \mathrm{~cm}$; TG mice, $1675 \pm 107 \mathrm{~cm} ; n=18$ and 15 , 10 -week-old mice; $p=0.49$, unpaired Student's $t$ test). Therefore, this result also suggests that TG mice show reduced anxietylike behavior than WT mice.

\section{Antidepressant-like effects of VEGF}

In clinical cases of mood disorders, depression often accompanies anxiety and vice versa (Paul, 1988). Therefore, we attempted to analyze the level of depression-like behaviors in the Porsolt forced swim test that has been widely used for the assessment of antidepressant drugs (Porsolt et al., 1977) (Fig. 7A). Mice were placed in an inescapable cylinder half-filled with water to induce the behavioral state of despair. We measured the periods of immobile status ("freezing"), in which longer freezing periods indicate higher degrees of depression-like status. We found that TG mice had significantly less freezing time compared with controls (freezing time: WT mice, $63.4 \pm 2.0 \%$; TG mice, $40.9 \pm 4.0 \%$; $n=20$ and 19, 10-week-old mice; $p<0.0001$, Welch's $t$ test). This result suggests that TG mice may be more resistant to depressionlike status, which is in good agreement with a recent report that a pharmacological application of VEGF receptor antagonists suppressed the behavioral effects of antidepressant drugs in rats (Warner-Schmidt and Duman, 2007).

\section{VEGF reduces fear-related behavior}

We have further examined fear-related behaviors in TG mice (Fig. $7 B$ ). On the first day, mice were placed in a conditioning chamber, and auditory stimuli [conditioned stimulus (CS): white noise, $55 \mathrm{~dB}, 30 \mathrm{~s}$ ] paired with electric footshocks [unconditioned stimulus (US): $0.2 \mathrm{~mA}, 2 \mathrm{~s}$; during the last $2 \mathrm{~s}$ of auditory stimuli] were presented three times at 1,3 , and $5 \mathrm{~min}$ (indicating the onset

\footnotetext{
$\leftarrow$

(Figure legend continued.) immature neurons were localized in the innermost layer of $\mathrm{GCL}$. In contrast, many immature neurons are scattered within $\mathrm{GCL}$ in TG mice. Dendritic arbor of immature neurons appeared to be more developed in TG mice. Similarly, 4-week-survived BrdUlabeled cells (many of them differentiated into neurons) were found in the inner layer of $\mathrm{GCL}$ in WT mice, but they were also found in the middle or even outer layer of $\mathrm{GCL}$ in TG mice. $\boldsymbol{D}$ Differentiation of newborn cells in GCL. Dividing cells in 6-week-old mice were labeled with BrdU, and they were allowed to differentiate for 4 weeks. Brain slices were triple stained for BrdU (red, 4-week-old young cells), NeuN (green, neurons), and GFAP (blue, astrocytes). The images show a region of dentate gyrus in WT (left) and TG (right) mice. $\boldsymbol{E}$, Quantification of cell types. The graph indicates the percentages of BrdU-labeled neurons, astrocytes, and other cells in $\mathrm{GCL}$. Most of the newborn cells had differentiated into neurons (80\%). There was no difference between genotypes. $n=16$ slices from 4 mice per group, 10-week-old mice. Nonsignificant for neurons, astrocytes, or other cell types between WT and TG mice by the Steel-Dwass's test. Data are as follows: neurons: WT mice, $80.2 \pm 2.3 \%$; TG mice, $76.5 \pm 2.9 \%$; astrocytes: WT mice, $0.6 \pm 0.5 \%$; TG mice, $0.5 \pm 0.3 \%$; other cell types: WT mice, $19.2 \pm 2.1 \%$; TG mice, $23.0 \pm 3.0 \%$. Scale bars: $\boldsymbol{A}, 200 \mu \mathrm{m} ; \boldsymbol{C}, 50 \mu \mathrm{m}$ (left), $25 \mu \mathrm{m}$ (right); $\boldsymbol{D}, 50 \mu \mathrm{m}$.
}

of auditory stimuli). Both WT and TG mice showed a gradual increase in fear responses (freezing behavior). However, the degree of freezing behaviors was considerably reduced in TG mice (genotype effect: $F_{(1,22)}=18.88, p<0.001$; bin effect: $F_{(6,132)}=$ $68.45, p<0.001$; interaction effect of genotype $\times$ bin: $F_{(6,132)}=$ 7.57, $p<0.001$; two-way repeated-measure ANOVA; comparisons between genotypes: $p<0.05$ for bins $4-7$, one-way ANOVA followed by Tukey-Kramer's post hoc test; $n=14$ and 10 for 10-week-old WT and TG mice). On the second day, mice were placed in the same conditioning chamber, and context-induced fear was assessed for $2 \mathrm{~min}$. Both genotypes showed freezing responses at the similar levels as observed on the first day (comparisons between bin 7 on dayl and bin 1 on day 2 were nonsignificant for both genotypes; one-way ANOVA followed by TukeyKramer's post hoc test; $n=14$ and 10 for 10 -week-old WT and TG mice), although the level of freezing was consistently lower in TG mice (genotype effect: $F_{(1,22)}=9.75, p<0.01$; no interaction or bin effect, two-way repeated measure ANOVA; $n=14$ and 10 for 10-week-old WT and TG mice). On the third day, when the mice were transferred to a different chamber, they moved more freely. However, presentation of the auditory cue (white noise for $120 \mathrm{~s}$, in bins 3-4) specifically induced freezing responses in both groups (genotype effect: $F_{(1,22)}=0.91, p=0.35$; bin effect: $F_{(5,110)}$ $=24.80, p<0.0001$; interaction effect of genotype $\times$ bin: $F_{(5,110)}$ $=1.19, p=0.32$; two-way repeated-measure ANOVA; comparisons between bins 1 and 3: $p<0.01$ for both genotypes, one-way ANOVA followed by Tukey-Kramer's post hoc test; $n=14$ and 10 for 10-week-old WT and TG mice). Together, the induction of fear may be reduced in TG mice, whereas the associative learning per se remains intact.

\section{VEGF120 TG mice are less aggressive}

During the routine maintenance of mouse colonies, we have noticed that TG mice are more passive and seldom participate in fighting. Therefore, we performed a resident-intruder aggression assay to quantitatively evaluate aggressive behaviors in 15-weekold mice (supplemental Fig. 5, available at www.jneurosci.org as supplemental material). WT resident mice that were individually housed for 4 weeks before testing exhibited territory-protecting aggression against intruder mice (e.g., biting, clawing, lunging, and aggressive pinning). As expected, TG mice seldom attacked the intruder mice as indicated by the number of attacks, duration of attacks, and latency to initiate attacks (data and statistical analyses are described in the figure legend for supplemental Fig. 5, available at www.jneurosci.org as supplemental material). In TG mice, the social behaviors such as sniffing or following the intruders were normal. These results suggest that VEGF efficiently suppresses aggressive behaviors.

\section{Basal locomotive activities are normal}

Because of distinct alterations in mood-related behavior, we wonder whether TG mice also act differently under natural conditions. Therefore, we attempted to monitor the basal locomotive activities in home cages by counting the number of line-crossings for 3 consecutive days (Fig. 7C). However, we found no significant difference between WT and TG mice in the total locomotive activities in their home cages (total line-crossings on days 2-3: WT mice, $1.30 \pm 0.19 \times 10^{3}$ counts; TG mice, $1.71 \pm 0.38 \times 10^{3}$ counts; $n=9$ per group, 10 -week-old mice; $p=0.07$ by unpaired Student's $t$ test), although a slight increase in nighttime activities was observed in TG mice (activities at night: WT mice, $67.7 \pm$ $5.8 \%$; TG mice, $84.0 \pm 2.8 \% ; n=9$ per group, 10 -week-old mice; $p<0.05$, unpaired Student's $t$ test). Thus, the basal activities 
under natural conditions were found to be similar in WT and TG mice.

\section{Dissociation between the level of adult neurogenesis and mood-related behaviors}

To investigate the relationships between hippocampal neurogenesis and moodrelated behaviors, we also examined 30 week-old mice ("older mice") in the elevated plus maze, forced swim test, and fear conditioning (Fig. 8). Because hippocampal neurogenesis in TG mice declines to the control levels by 20 weeks of age (Fig. $5 B$ ), we have speculated that anxiolyticlike or antidepressant-like effects of VEGF might be reduced or diminished in 30week-old mice.

In the elevated plus maze (Fig. $8 A$ ), contrary to our expectation, TG mice still displayed a higher tendency to explore open arms than WT controls (time on open arms: WT mice, $6.3 \pm 2.1 \%$; TG mice, $29.6 \pm 6.9 \% ; n=20$ and 15,30 week-old mice; $p<0.01$, Mann-Whitney $U$ test), whereas the total distances were not different (total distance: WT mice, $1326 \pm 88 \mathrm{~cm}$; TG mice, $1548 \pm 112 \mathrm{~cm}$; $n=20$ and 15, 30-week-old mice; $p=$ 0.12 , unpaired Student's $t$ test). This result suggests that the anxiolytic-like effect of VEGF is maintained in older TG mice.

Similarly, in the forced swim test (Fig. $8 B)$, we found that the total freeze time (percentage) was significantly reduced in TG mice (total freeze time: WT mice, $68.1 \pm 1.6 \%$; TG mice, $44.3 \pm 5.3 \% ; n=$ 20 and 18, 30-week-old mice; $p<0.001$, Mann-Whitney $U$ test), suggesting that VEGF continuously exerts antidepressantlike effects in older mice.

In fear conditioning (Fig. 8C), we also observed the similar behaviors in older TG mice. When a series of electric footshocks was delivered on day 1, a gradual increase in freezing responses was observed in older WT mice but not in older TG mice (comparisons between genotypes, $p<0.01$ for bins 6 and 7; comparisons between bins 1 and $7, p<0.01$ for WT mice and nonsignificant for TG mice; one-way ANOVA followed by Tukey-Kramer's post hoc test; $n=20$ and 14 for 30-week-old WT and TG mice). Although the older TG mice failed in this classical conditioning, we examined context-induced fear on the following day. The freezing percentages on day 2 were found to be similar to those at the end of conditioning on day 1 in WT and TG mice (genotype effect: $F_{(1,32)}=101.79, p<0.001$; no bin or interaction effect; two-way repeated-measure ANOVA; comparisons between bin 7 on day1 and bin 1 on day 2: nonsignificant for both genotypes, one-way ANOVA followed by Tukey-Kramer's post hoc test; $n=20$ and 14 for 30-week-old WT and TG mice). Thus, the reduction in freezan internal control.

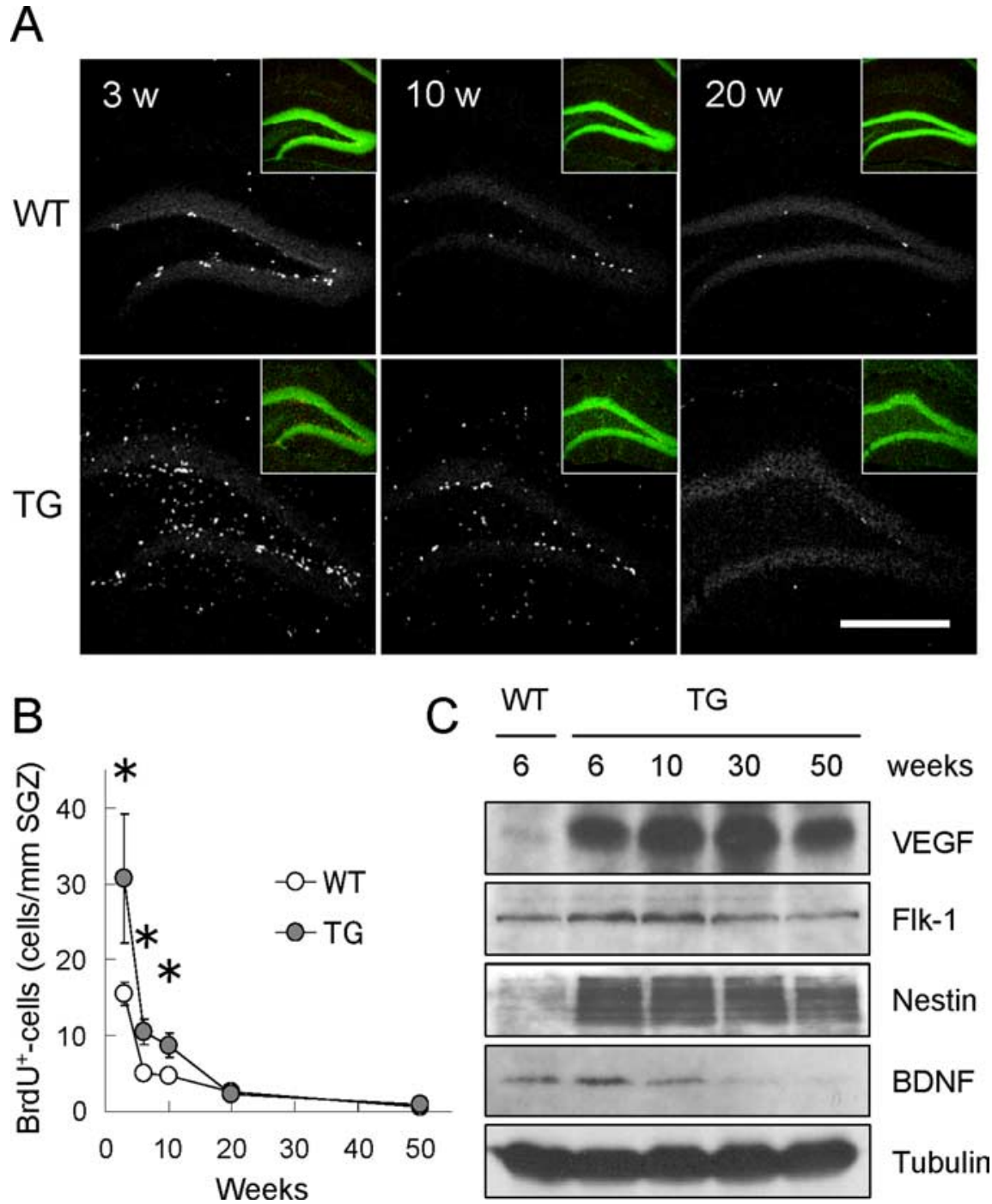

Figure 5. Reduced cell proliferation in older VEGF120-TG mice. $\boldsymbol{A}$, Age-dependent reduction of cell proliferation in dentate gyrus. Animals at 3, 10, and 20 weeks (w) of age were killed $2 \mathrm{~h}$ after a single injection of BrdU. Proliferating cells in dentate gyrus of WT (top) and TG (bottom) mice were visualized by immunostaining for BrdU (white dots). Insets show nuclear staining (green) of the presented images. Scale bar, $500 \mu \mathrm{m}$. B, Quantification of proliferating cells along SGZ. The graph indicates the densities of BrdU-positive cells along SGZ at different time points $(3,6,10,20$, and 50 weeks of age). Cell proliferation in dentate gyrus was reduced with age in both WT and TG mice. Cell proliferation in TG mice declined to the control levels by 20 weeks of age. ${ }^{*} p<0.05$ by statistical analysis (see data). Data for BrdU-positive cell densities are as follows: 3 weeks old: WT mice, $15.50 \pm 1.43$ cells $/ \mathrm{mm}$ SGZ; TG mice, $30.65 \pm 8.02$ cells $/ \mathrm{mm} \mathrm{SGZ;} n=9$ mice per group; $p<0.05$, Mann-Whitney U test; 6 weeks old: WT mice, $4.98 \pm$ 0.58 cells $/ \mathrm{mm} \mathrm{SGZ;TG} \mathrm{mice,} 10.47 \pm 1.63$ cells $/ \mathrm{mm} \mathrm{SGZ;} n=10$ mice per group; $p<0.01$, Welch's $t$ test; 10 weeks old: WT mice, $4.74 \pm 0.46$ cells $/ \mathrm{mm} \mathrm{SGZ;} \mathrm{TG} \mathrm{mice,} 8.70 \pm 1.48$ cells $/ \mathrm{mm} \mathrm{SGZ;} n=7$ mice per group; $p<0.05$, Welch's $t$ test; 20 weeks old: WT mice, $2.51 \pm 0.20$ cells $/ \mathrm{mm} \mathrm{SGZ;} \mathrm{TG} \mathrm{mice,} 2.24 \pm 0.81$ cells $/ \mathrm{mm} \mathrm{SGZ;} n=6$ mice per groups; $p=0.11$, Mann-Whitney $U$ test; 50 weeks old: WT mice, $0.68 \pm 0.19$ cells $/ \mathrm{mm} \mathrm{SGZ;TG} \mathrm{mice,} 0.96 \pm 0.34$ cells $/ \mathrm{mm} \mathrm{SGZ;} n=4$ mice per group; $p=0.50$, unpaired Student's $t$ test; independent experiments at each time point. C, Persistent expression of VEGF120 and Flk-1 (VEGF receptor 2) in VEGF120-TG mice. Hippocampal protein extracts from TG mice $(6,10,30$, and 50 weeks old) and WT mice (6 weeks old) were analyzed by Western blot for VEGF, Flk-1, Nestin, BDNF, and $\beta$-tubulin. The result showed consistent expression of VEGF120 (mature form is shown) and Flk-1 in TG mice. In contrast, the level of Nestin and BDNF tended to decline with age (see also supplemental Fig. 4, available at www.jneurosci.org as supplemental material, for quantitative analyses). $\beta$-Tubulin was used as

ing behavior is consistent in TG mice, but it seems more exaggerated at 30 weeks of age. Although behavioral responses to the electric footshocks (such as jumping) looked similar in both genotypes, attenuation of neuropathic pain might account for the reduced freezing behavior in TG mice. To clarify this issue, we performed a hot plate test at $55^{\circ} \mathrm{C}$ and measured the latency to the hindpaw lick or shake/flutter as an indicator of thermal nociception (Fig. $8 D$ ). The data suggest that TG mice are not insensitive 


\section{A Open field test (10-week-old mice)}
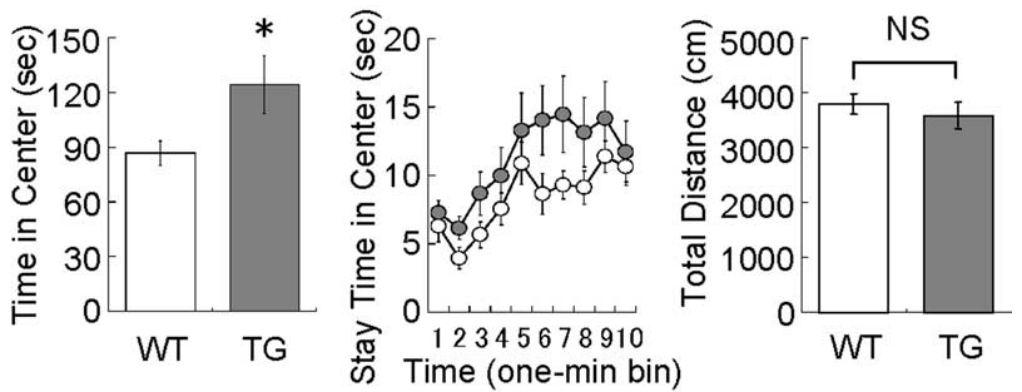

\section{B Elevated plus maze (10-week-old mice)}
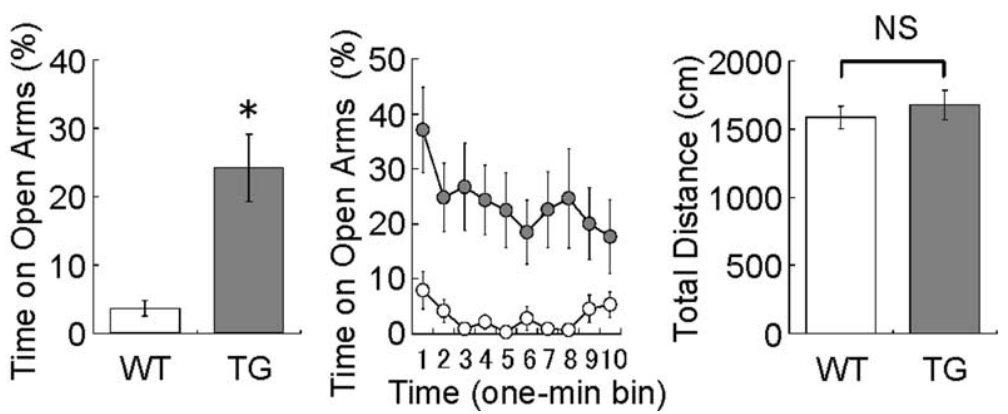

Figure 6. Anxiolytic-like behavior in VEGF120-TG mice. The behavioral tests were performed in 10-week-old male mice. WT littermates were used as controls (white, WT mice; gray, TG mice). $\boldsymbol{A}$, Open-field test. Total time in the center area (in seconds), stay time in the center area per $1 \mathrm{~min}$ bin (in seconds), and total distance (in centimeters) during the 10 min test period are shown. TG mice more often explored the center area than WT mice. The total distances traveled during the test period were similar between genotypes. $n=19$ and 18 for 10 -week-old WT and TG mice. ${ }^{*} p<0.05$ and nonsignificant $(p=0.38)$, unpaired Student's $t$ test. Data are as follows: time in center: WT mice, $86.6 \pm 6.7 \mathrm{~s}$; TG mice, $124.3 \pm 15.9 \mathrm{~s}$; total distance: WT mice, $3675 \pm 152 \mathrm{~cm}$; TG mice, $3302 \pm 249 \mathrm{~cm}$. B , Elevated plus maze. Total time on open arms (percentage), time on open arms per $1 \mathrm{~min}$ bin (percentage), and total distance (in centimeters) during the $10 \mathrm{~min}$ test period are shown. TG mice spent a significantly longer time on open arms than WT mice. The total distances traveled during the test period were similar. $n=18$ and 15 for 10 -week-old WT and TG mice. ${ }^{*} p<0.0001$, Mann-Whitney U test; $p=0.49$ (nonsignificant), unpaired Student's $t$ test. Data are as follows: time on open arms: WT mice, $3.63 \pm 1.2 \%$; TG mice, $24.2 \pm 4.9 \%$; total distance: WT mice, $1583 \pm 82 \mathrm{~cm}$; TG mice, $1675 \pm 107 \mathrm{~cm}$. NS, Nonsignificant.

but are slightly more sensitive to thermal nociception (latency of thermal response: WT mice, $18.1 \pm 1.21 \mathrm{~s}$; TG mice, $10.7 \pm$ $1.78 \mathrm{~s} ; n=20$ and 14, 30-week-old mice; $p<0.01$, unpaired Student's $t$ test). Therefore, the reduced freezing response in TG mice is not attributed to reduced neuropathic pain.

Collectively, these behavioral results suggest that the characteristic behavioral phenotypes are maintained in older TG mice. Therefore, it indicates that the degree of hippocampal neurogenesis is not always correlated with mood-related behaviors. A similar implication can be drawn from the data of WT mice that the anxiety- or depression-like behavior seems to be unchanged between 10 and 30 weeks of age despite differences in hippocampal neurogenesis (Figs. 5-8). Thus, the degree of adult neurogenesis and affective behaviors may not be correlated directly.

\section{Discussion}

In the present study, we have demonstrated the effects of VEGF on hippocampal neurogenesis and affective behaviors for the first time in genetically modified mice. Our data provided novel insights into the functional roles of VEGF in hippocampal neurogenesis, affective behaviors, and their correlation.
VEGF for hippocampal neurogenesis

VEGF and its receptors are expressed in a variety of cells in brain including neurons, astrocytes, and NPCs (Stone et al., 1995; Maurer et al., 2003; Cao et al., 2004). VEGF has been shown to directly stimulate cell proliferation of NPCs in cell cultures (Jin et al., 2002), and more recently, the pharmacological application or virusmediated gene transfer of VEGF has shown to enhance hippocampal neurogenesis in animals (Cao et al., 2004; WarnerSchmidt and Duman, 2007). Consistently, in this study, the characterization of TG mice overexpressing VEGF120 in forebrain has clearly demonstrated that VEGF exerts a strong neurogenic effect in adult brain (Fig. 4). Adult neurogenesis in hippocampus was almost doubled, and the development of immature neurons was accelerated in these mice.

Unexpectedly, however, we found that hippocampal neurogenesis in TG mice rapidly declined with age and reduced to the control levels by 20 weeks of age (Fig. $5 B)$. This result indicates that VEGF alone is not sufficient to support long-term enhancement of adult neurogenesis and that angiogenesis per se does not necessarily predict enhanced neurogenesis. A failure to support prolonged enhancement of adult neurogenesis was not attributable to a reduction in VEGF120 expression nor downregulation of Flk-1 in hippocampus (Fig. 5C). One interpretation of these results is that activation of multiple signaling pathways is necessary to sustain prolonged proliferation of NPCs in hippocampus. Other growth factors such as BDNF and insulin-like growth factor 1 are also known as potent enhancers of adult neurogenesis (Trejo et al., 2001; Rossi et al., 2006). Therefore, it is possible that these growth factors may act together to support proliferation of NPCs in adult brain. Age-dependent declines of these factors might partly explain a reduced level of neurogenesis in elders. Indeed, a gradual reduction in BDNF expression has been observed in TG mice (Fig. 5C). An alternative interpretation of our results is that NPCs in hippocampus do not have self-replicating abilities or naturally lose such abilities with age. This possibility is suggested by a recent report that hippocampal NPCs may not be neural stem cells capable of self-replication (Bull and Bartlett, 2005). Without replenishment of NPCs, chronic stimulation of adult neurogenesis would eventually exhaust NPCs. In both interpretations, intrinsic properties of hippocampal NPCs seem to be most critical. With the aim of long-lasting enhancement of adult neurogenesis, it is a key issue to endow NPCs with selfreplicating abilities for extended periods.

\section{VEGF for affective behaviors}

This study has also provided direct evidence that VEGF influences mood-related behaviors. Overexpression of VEGF120 in forebrain has resulted in antidepressant-like behavior (Fig. 7A), which is in good agreement with a recent pharmacological report 
showing that antagonists of VEGF receptors block behavioral effects of antidepressant drugs (Warner-Schmidt and Duman, 2007). In addition to antidepressant-like effects, we have demonstrated for the first time that VEGF reduces anxiety-like behavior as well as induction of fear (Figs. 6, $7 B)$. Furthermore, we also provided evidence that VEGF suppresses aggressive behaviors (supplemental Fig. 5, available at www.jneurosci.org as supplemental material). Despite these dramatic alterations in affective behaviors, the basal activities under natural conditions (Fig. 7D) and the social activities observed during the aggression assay (supplemental Fig. 5, available at www.jneurosci.org as supplemental material) were similar between genotypes.

Clinical cases of mood disorders in humans suggest that affective behaviors such as depression and anxiety are interrelated. Similarly, we found that VEGF alters several forms of affective behaviors (e.g., depression- and anxiety-like behaviors, aggression, and fear). However, the neural mechanisms that explain such concurrent changes remain unknown. Subcortical structures including amygdala and hippocampus are known to be involved in regulation of mood. Because VEGF120 is overexpressed in both amygdala and hippocampus, normal functions of these structures might be affected in TG mice. However, we at least found that TG mice were able to express conditioned fear induced by contexts or auditory cues, suggesting that some functional aspects of amygdala or hippocampus remain intact (Fig. 7B). Because behavioral analyses may be insufficient to dissect out the precise neural correlates, different approaches are necessary to address this issue.

We are currently investigating the molecular mechanism how VEGF affects mood. The hypothalamus-pituitary-adrenal axis of hormonal system is known to participate in stress responses and modulation of mood (Young, 2004). External stresses increase the level of glucocorticoids (e.g., cortisol), and these stress hormones are often elevated in depressed patients. We have tested this possibility by measuring the plasma contents of cortisol in the basal state, under constraint stress and after the recovery from stress in mice (supplemental Fig. 6, available at www. jneurosci.org as supplemental material). In both genotypes, plasma contents of cortisol significantly increased after restraint stress and reduced to near basal levels $1 \mathrm{~h}$ after the end of stress. The cortisol levels between genotypes were similar in any of these measures (see supplemental Fig. 2,

\section{A Forced swim test (10-week-old mice)}

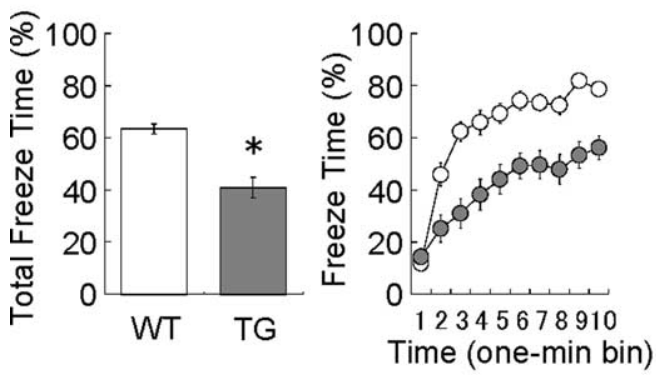

\section{B Fear-related response (10-week-old mice)}
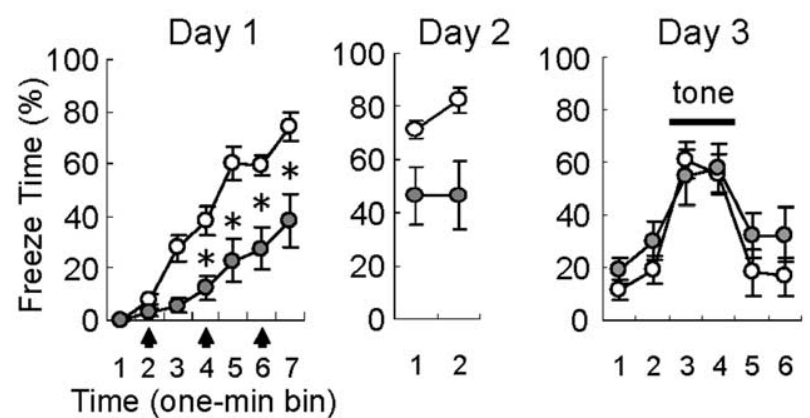

Time (one-min bin)

\section{Basal locomotive activity (10-week-old mice)}
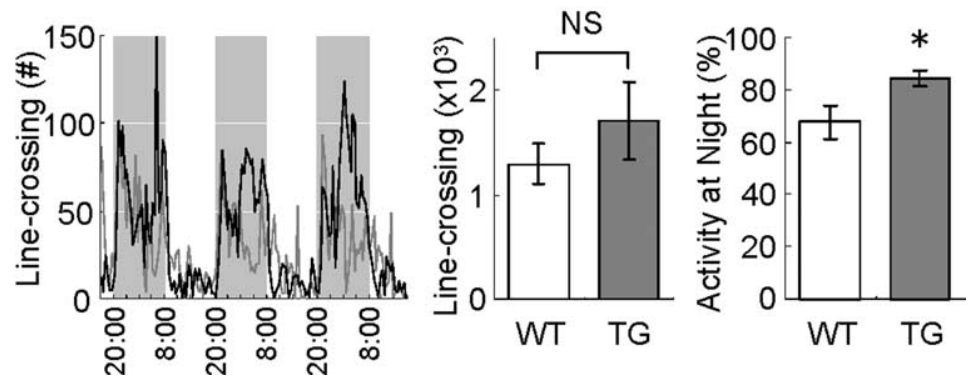

Figure 7. Antidepressant-like behavior and reduced fear in VEGF120-TG mice. The behavioral tests were performed in 10-week-old male mice. WT littermates were used as controls (white, WT mice; gray, TG mice). A, Porsolt forced swim test. Total freeze time (in percentage) and freeze time per $1 \mathrm{~min}$ bin (in percentage) are shown. The freezing time was significantly reduced in TG mice. $n=20$ and 19 for 10-week-oldWT and TG mice. * $p<0.0001$, Welch's ttest. Data are asfollows: freeze time:WT mice, 63.4 $\pm 2.0 \%$; TG mice, $40.9 \pm$ $4.0 \%$. B, Fear conditioning. The freeze time per $1 \mathrm{~min}$ bin (in percentage) is shown for days 1-3. 0n day 1, mice were placed in a conditioning chamber, and auditory stimuli (CS: white noise, $55 \mathrm{~dB}, 30 \mathrm{~s}$ ) paired with electric footshocks (US, $0.2 \mathrm{~mA}, 2 \mathrm{~s}$; during the last $2 \mathrm{~s}$ of auditory stimuli; arrows) were presented at 1,3 , and $5 \mathrm{~min}$ (indicating the onset of tone). Induction of fear was significantly reduced in TG mice. $n=14$ and 10 for 10 -week-old WT and TG mice. ${ }^{*} p<0.01$ for bins 4-7, one-way ANOVA followed by Tukey-Kramer's posthoc test. Data on day 1 in WT and TG mice are as follows: bin 1, $0.0 \pm 0.0$ and $0.3 \pm 0.3 \%$; bin 2, $8.2 \pm 2.2$ and $3.0 \pm 1.2 \%$; bin 3, $27.8 \pm 4.6$ and $5.6 \pm 2.6 \%$; bin 4, $38.3 \pm 5.6$ and $12.7 \pm 4.3 \%$; bin 5,60.3 \pm 6.1 and $22.8 \pm 7.7 \%$; bin 6, $59.3 \pm 4.0$ and $27.6 \pm 7.8 \%$; bin 7, $74.2 \pm 5.2$ and $38.1 \pm 9.7 \%$. On day 2 , mice were placed in the same conditioning chamber, and context-induced fear was assessed for $2 \mathrm{~min}$. Both genotypes showed a similar level of freezing responses as observed on day 1. $n=14$ and 10 for 10-week-old WT and TG mice. Data were nonsignificant between bin 7 on day 1 and bin 1 on day 2 in both genotypes (one-way ANOVA followed by Tukey-Kramer's post hoc test); data on day 2 in WT and TG mice were as follows: bin 1,71.0 \pm 3.3 and $46.2 \pm 10.1 \%$; bin 2, $82.3 \pm 4.5$ and 46.5 $\pm 11.9 \%$. 0 n day 3 , mice were placed in a different chamber, and cue-induced fear was examined (auditory cue was presented for 2 min corresponding to bins 3-4; horizontal bar). Freezing response was observed during the tone presentation in both genotypes. $n=14$ and 10 for 10-week-old WT and TG mice. $p<0.01$ between bin 1 and 3 in both genotypes (one-way ANOVA followed by Tukey-Kramer's post hoc test). Data on day 3 in WT and TG mice are as follows: bin 1, $11.5 \pm 3.5$ and $19.0 \pm 4.7 \%$; bin 2, $19.1 \pm 5.2$ and 30.1 \pm 6.9\%; bin 3, 60.9 \pm 6.9 and $54.5 \pm 9.9 \%$; bin 4, $55.5 \pm 7.1$ and $57.4 \pm 9.2 \%$; bin $5,18.2 \pm 8.4$ and $32.2 \pm 8.2 \%$; bin $6,16.6 \pm 6.7$ and $32.5 \pm 9.8 \%$. C, Basal locomotive activities under natural conditions. Mouse activities in home cages were measured by counting the number of linecrossings (infrared beam detection). The graphs (left) show the activities per $30 \mathrm{~min}$ block for 3 consecutive days in WT (gray line) and TG (black line) mice. Shadows represent $12 \mathrm{~h}$ dark periods (8:00 P.M. to 8:00 A.M.). Total line-crossings on days 2-3 (center) and percentages of activities at night on days 2-3 (right) are shown. No significant change was observed for the total locomotive activities in WT and TG mice, but the percentage of nighttime activities was slightly increased in TG mice. $n=9$ per group, 10-week-0ld mice. $p=0.07$ [nonsignificant (NS)] and * $p<0.05$, unpaired Student's $t$ test. Data are as follows: total line-crossings: WT mice, $1.30 \pm 0.19 \times 10^{3}$ counts; TG mice, $1.71 \pm 0.38 \times 10^{3}$ counts; activities at nighttime: WT mice, $67.7 \pm 5.8 \%$; TG mice, $84.0 \pm 2.8 \%$. 


\section{A Elevated plus maze (30-week-old mice)}
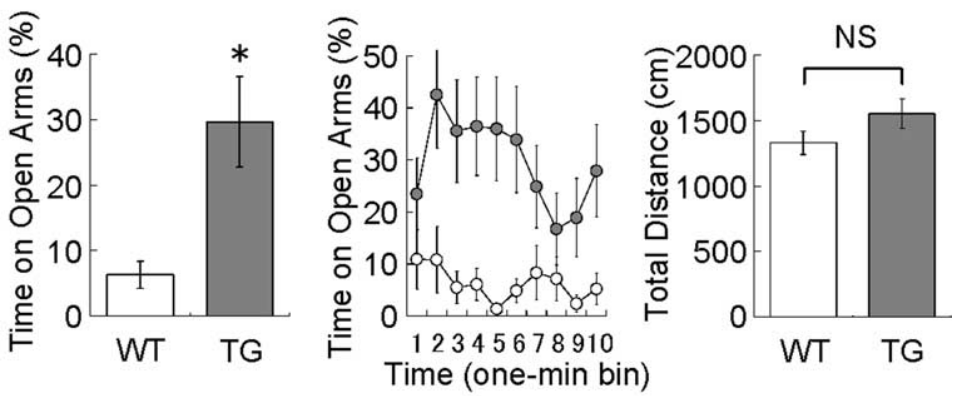

\section{B Forced swim test (30-week-old-mice)}
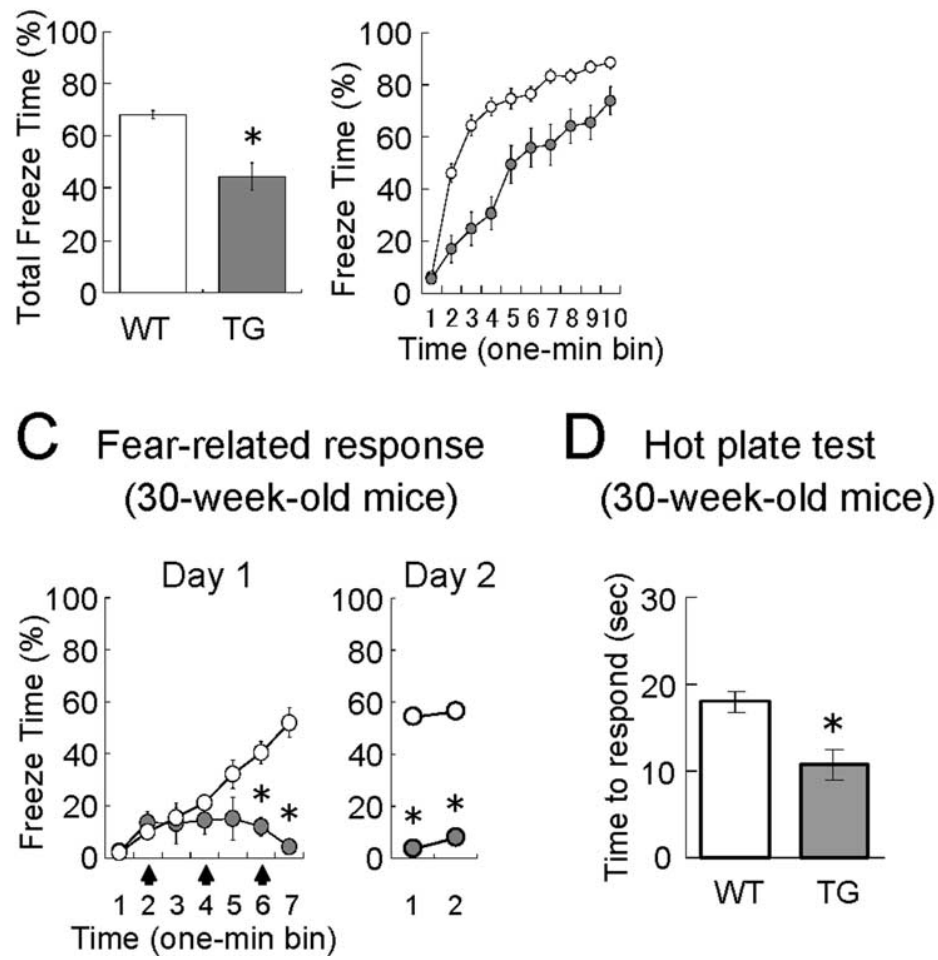

Figure 8. Affective behaviors in older VEGF120-TG mice. The behavioral tests were performed in 30-week-old male mice (white, WT mice; gray, TG mice). The characteristic behavioral phenotypes of TG mice were maintained at 30 weeks of age under a minimal level of neurogenesis. $\boldsymbol{A}$, Elevated plus maze. Time on the open arms (in percentage), time on the open arms per 1 min bin (in percentage), and total distance (in centimeters) during the 10 min test period are shown. $n=20$ and 15 for 30-week-old WT and TG mice. ${ }^{*} p<0.01$ Mann-Whitney U test; $p=0.12$ [nonsignificant (NS)], unpaired Student's $t$ test. Data are as follows: time on open arms: WT mice, $6.3 \pm$ 2.1\%; TG mice, $29.6 \pm 6.9 \%$; total distance; WT mice, $1326 \pm 88 \mathrm{~cm}$; TG mice, $1548 \pm 112 \mathrm{~cm}$. $\boldsymbol{B}$, Porsolt forced swim test. Total freeze time (in percentage) and freeze time per $1 \mathrm{~min}$ bin (in percentage) during the 10 min test period are shown. $n=20$ and $18 \mathrm{for} 30$-week-old WT and TG mice. ${ }^{*} p<0.001$, Mann-Whitney Utest. Data are as follows: total freeze time:WT mice, $68.1 \pm 1.6 \% ;$ TG mice, $44.3 \pm 5.3 \%$. C, Fear conditioning. Freeze time per $1 \mathrm{~min}$ bin (in percentage) is shown for day 1 (conditioning) and day 2 (context-induced fear). $n=20$ and 14 for 30-week-old WT and TG mice. * $p<0.01$ for bins $6-7$ on day 1 and bins $1-2$ on day 2 (one-way ANOVA followed by Tukey-Kramer's post hoc test). Data on day 1 in WT and TG mice are as follows: bin 1, $2.3 \pm 1.0$ and $2.7 \pm 1.8 \%$; bin 2, $10.0 \pm 1.7$ and $13.7 \pm 4.0 \%$; bin $3,15.5 \pm 3.8$ and $13.3 \pm 7.6 \%$; bin $4,21.2 \pm 2.7$ and $14.7 \pm 5.3 \%$; bin $5,32.2 \pm 5.2$ and $15.2 \pm 7.9 \%$; bin $6,40.6 \pm$ 4.3 and $12.1 \pm 3.5 \%$; bin 7, $52.1 \pm 5.5$ and $4.3 \pm 2.2 \%$. Data were nonsignificant between bin 7 on day 1 and bin 1 on day 2 in both genotypes (one-way ANOVA followed by Tukey-Kramer's posthoc test). Data on day 2 in WT and TG mice are as follows: bin 1,54.3 \pm 4.1 and $3.8 \pm 1.4 \%$; bin 2, 56.2 \pm 5.1 and $7.6 \pm 2.9 \%$. D , Hot plate test. Thirty-week-old male mice were placed on a hot plate maintained at $55^{\circ} \mathrm{C}$, and the latencies (in seconds) of thermal nociception (hindpaw lick or hindpaw shake/flutter) were measured. The result indicates that TG mice are not insensitive to nociceptive stimuli. $n=20$ and 14 for 30 -week-old WT and TG mice. ${ }^{*} p<0.01$, unpaired Student's test. Data are as follows: latencies: WT mice, $18.1 \pm 1.21 \mathrm{~s} ; \mathrm{TG}$ mice, $10.7 \pm 1.78 \mathrm{~s}$.

available at www.jneurosci.org as supplemental material, for data and statistical analyses). Thus, the altered behaviors in TG mice may not be explained by the changes in neuroendocrine system for stress response.
We also examined the tissue contents of serotonin (5-HT) and norepinephrine (NE) because a deficiency of monoamines such as 5 -HT and NE in brain has been suggested to be an etiology of clinical depression (Schildkraut, 1965; Coppen, 1967). We expected that the level of monoamines might be higher in TG mice, but our preliminary results from ELISA showed that tissue contents of 5-HT or NE were not increased in TG mice (data not shown). Thus, the behavioral consequence of VEGF expression may not be attributed to the elevation of monoamine contents. Although the molecular mechanisms of VEGF in affective behaviors have yet to be elucidated, it is tempting to speculate that VEGF might be a common signaling molecule for different forms of affective behaviors.

\section{Correlation of hippocampal} neurogenesis and affective behavior Finally, this study also provided insights into the correlation of adult neurogenesis and depression-like behavior. A role of adult neurogenesis in antidepressant actions has been implicated by a number of studies (for review, see Sahay and Hen, 2007). A pharmacological analysis by Warner-Schmidt and Duman (2007) has shown that an inhibition of Flk-1mediated VEGF signaling blocked both neurogenesis and antidepressant effects. Consistent with this report, we observed enhanced hippocampal neurogenesis as well as antidepressant-like behavior in TG mice (Figs. 4, 7B). Unexpectedly, however, antidepressant-like behavior was still present under a minimal level of hippocampal neurogenesis in aged TG mice (Fig. $8 \mathrm{~B}$ ). In fact, even in older WT mice, declined hippocampal neurogenesis does not seem to result in elevated levels of depression-like behavior or anxiety-like behavior (Figs. 7, 8). Thus, our data indicate that the level of adult neurogenesis and the expression of antidepressant-like behavior are not correlated directly. Although these findings seem to conflict with a previous report showing that adult neurogenesis is required for the behavioral effects of antidepressant drugs (Santarelli et al., 2003), our present data have not excluded the possibility that neurons generated during juvenile stages might have contributed to antidepressant-like behavior in older animals. Therefore, additional analyses are necessary to address the issue whether VEGF has bifurcated (or independent) pathways for adult neurogenesis and antidepressant behavior.

In summary, we have demonstrated that VEGF exerts pleiotropic effects on brain functions including enhancement of adult 
neurogenesis and modulation of mood. Our findings provide valuable insights into the molecular mechanisms underlying affective behaviors.

\section{References}

Bull ND, Bartlett PF (2005) The adult mouse hippocampal progenitor is neurogenic but not a stem cell. J Neurosci 25:10815-10821.

Cao L, Jiao X, Zuzga DS, Liu Y, Fong DM, Young D, During MJ (2004) VEGF links hippocampal activity with neurogenesis, learning and memory. Nat Genet 36:827-835.

Coppen A (1967) The biochemistry of affective disorders. Br J Psychiatry 113:1237-1264.

During MJ, Cao L (2006) VEGF, a mediator of the effect of experience on hippocampal neurogenesis. Curr Alzheimer Res 3:29-33.

Fabel K, Tam B, Kaufer D, Baiker A, Simmons N, Kuo CJ, Palmer TD (2003) VEGF is necessary for exercise-induced adult hippocampal neurogenesis. Eur J Neurosci 18:2803-2812.

Ferrara N, Carver-Moore K, Chen H, Dowd M, Lu L, O'Shea KS, PowellBraxton L, Hillan KJ, Moore MW (1996) Heterozygous embryonic lethality induced by targeted inactivation of the VEGF gene. Nature 380:439-442.

Francis F, Koulakoff A, Boucher D, Chafey P, Schaar B, Vinet MC, Friocourt G, McDonnell N, Reiner O, Kahn A, McConnell SK, Berwald-Netter Y, Denoulet P, Chelly J (1999) Doublecortin is a developmentally regulated, microtubule-associated protein expressed in migrating and differentiating neurons. Neuron 23:247-256.

Fujisawa H (2004) Discovery of semaphorin receptors, neuropilin and plexin, and their functions in neural development. J Neurobiol 59:24-33.

Gage FH (2002) Neurogenesis in the adult brain. J Neurosci 22:612-613.

Gage FH, Coates PW, Palmer TD, Kuhn HG, Fisher LJ, Suhonen JO, Peterson DA, Suhr ST, Ray J (1995) Survival and differentiation of adult neuronal progenitor cells transplanted to the adult brain. Proc Natl Acad Sci U S A 92:11879-11883.

Gould E, Beylin A, Tanapat P, Reeves A, Shors TJ (1999) Learning enhances adult neurogenesis in the hippocampal formation. Nat Neurosci 2:260-265.

Jin K, Zhu Y, Sun Y, Mao XO, Xie L, Greenberg DA (2002) Vascular endothelial growth factor (VEGF) stimulates neurogenesis in vitro and in vivo. Proc Natl Acad Sci U S A 99:11946-11950.

Kempermann G, Kuhn HG, Gage FH (1997) More hippocampal neurons in adult mice living in an enriched environment. Nature 386:493-495.

Kitamura T, Mishina M, Sugiyama H (2003) Enhancement of neurogenesis by running wheel exercises is suppressed in mice lacking NMDA receptor epsilon 1 subunit. Neurosci Res 47:55-63.

Kuhn HG, Dickinson-Anson H, Gage FH (1996) Neurogenesis in the dentate gyrus of the adult rat: age-related decrease of neuronal progenitor proliferation. J Neurosci 16:2027-2033.

Lendahl U, Zimmerman LB, McKay RD (1990) CNS stem cells express a new class of intermediate filament protein. Cell 60:585-595.

Lledo PM, Alonso M, Grubb MS (2006) Adult neurogenesis and functional plasticity in neuronal circuits. Nat Rev Neurosci 7:179-193.

Magavi SS, Leavitt BR, Macklis JD (2000) Induction of neurogenesis in the neocortex of adult mice. Nature 405:951-955.

Maurer MH, Tripps WK, Feldmann REJ, Kuschinsky W (2003) Expression of vascular endothelial growth factor and its receptors in rat neural stem cells. Neurosci Lett 344:165-168.

Mayford M, Wang J, Kandel ER, O’Dell TJ (1995) CaMKII regulates the frequency-response function of hippocampal synapses for the production of both LTD and LTP. Cell 81:891-904.

Mogil JS, Wilson SG, Bon K, Lee SE, Chung K, Raber P, Pieper JO, Hain HS, Belknap JK, Hubert L, Elmer GI, Chung JM, Devor M (1999) Heritabil- ity of nociception I: responses of 11 inbred mouse strains on 12 measures of nociception. Pain 80:67-82.

Moretti S, Boemi M, Catalano A (2006) Neuronal semaphorins regulate a primary immune response. Curr Neurovasc Res 3:295-305.

Neufeld G, Cohen T, Gengrinovitch S, Poltorak Z (1999) Vascular endothelial growth factor (VEGF) and its receptors. FASEB J 13:9-22.

Papavassiliou E, Gogate N, Proescholdt M, Heiss JD, Walbridge S, Edwards NA, Oldfield EH, Merrill MJ (1997) Vascular endothelial growth factor (vascular permeability factor) expression in injured rat brain. J Neurosci Res 49:451-460.

Paul SM (1988) Anxiety and depression: a common neurobiological substrate? J Clin Psychiatry 49:13-16.

Porsolt RD, Bertin A, Jalfre M (1977) Behavioral despair in mice: a primary screening test for antidepressants. Arch Int Pharmacodyn Ther 229:327-336.

Raab S, Beck H, Gaumann A, Yuce A, Gerber HP, Plate K, Hammes HP, Ferrara N, Breier G (2004) Impaired brain angiogenesis and neuronal apoptosis induced by conditional homozygous inactivation of vascular endothelial growth factor. Thromb Haemost 91:595-605.

Rossi C, Angelucci A, Costantin L, Braschi C, Mazzantini M, Babbini F, Fabbri ME, Tessarollo L, Maffei L, Berardi N, Caleo M (2006) Brainderived neurotrophic factor (BDNF) is required for the enhancement of hippocampal neurogenesis following environmental enrichment. Eur J Neurosci 24:1850-1856.

Sahay A, Hen R (2007) Adult hippocampal neurogenesis in depression. Nat Neurosci 10:1110-1115.

Santarelli L, Saxe M, Gross C, Surget A, Battaglia F, Dulawa S, Weisstaub N, Lee J, Duman R, Arancio O, Belzung C, Hen R (2003) Requirement of hippocampal neurogenesis for the behavioral effects of antidepressants. Science 301:805-809.

Schaeren-Wiemers N, Gerfin-Moser A (1993) A single protocol to detect transcripts of various types and expression levels in neural tissue and cultured cells: in situ hybridization using digoxigenin-labelled cRNA probes. Histochemistry 100:431-440.

Schildkraut JJ (1965) The catecholamine hypothesis of affective disorders: a review of supporting evidence. Am J Psychiatry 122:509-522.

Staton CA, Kumar I, Reed MW, Brown NJ (2007) Neuropilins in physiological and pathological angiogenesis. J Pathol 212:237-248.

Stone JIA, Alon T, Pe'er J, Gnessin H, Chan-Ling T, Keshet E (1995) Development of retinal vasculature is mediated by hypoxia-induced vascular endothelial growth factor (VEGF) expression by neuroglia. J Neurosci 15:4738-4747.

Thurston G, Baluk P, Hirata A, McDonald DM (1996) Permeability-related changes revealed at endothelial cell borders in inflamed venules by lectin binding. Am J Physiol 271:H2547-H2562.

Trejo JL, Carro E, Torres-Aleman I (2001) Circulating insulin-like growth factor I mediates exercise-induced increases in the number of new neurons in the adult hippocampus. J Neurosci 21:1628-1634.

van Praag H, Kempermann G, Gage FH (1999) Running increases cell proliferation and neurogenesis in the adult mouse dentate gyrus. Nat Neurosci 2:266-270.

Wang Y, Kilic E, Kilic U, Weber B, Bassetti CL, Marti HH, Hermann DM (2005) VEGF overexpression induces post-ischaemic neuroprotection, but facilitates haemodynamic steal phenomena. Brain 128:52-63.

Warner-Schmidt JL, Duman RS (2007) VEGF is an essential mediator of the neurogenic and behavioral actions of antidepressants. Proc Natl Acad Sci U S A 104:4647-4652.

Yasuhara T, Shingo T, Date I (2004) The potential role of vascular endothelial growth factor in the central nervous system. Rev Neurosci 15:293-307.

Young AH (2004) Cortisol in mood disorders. Stress 7:205-208. 